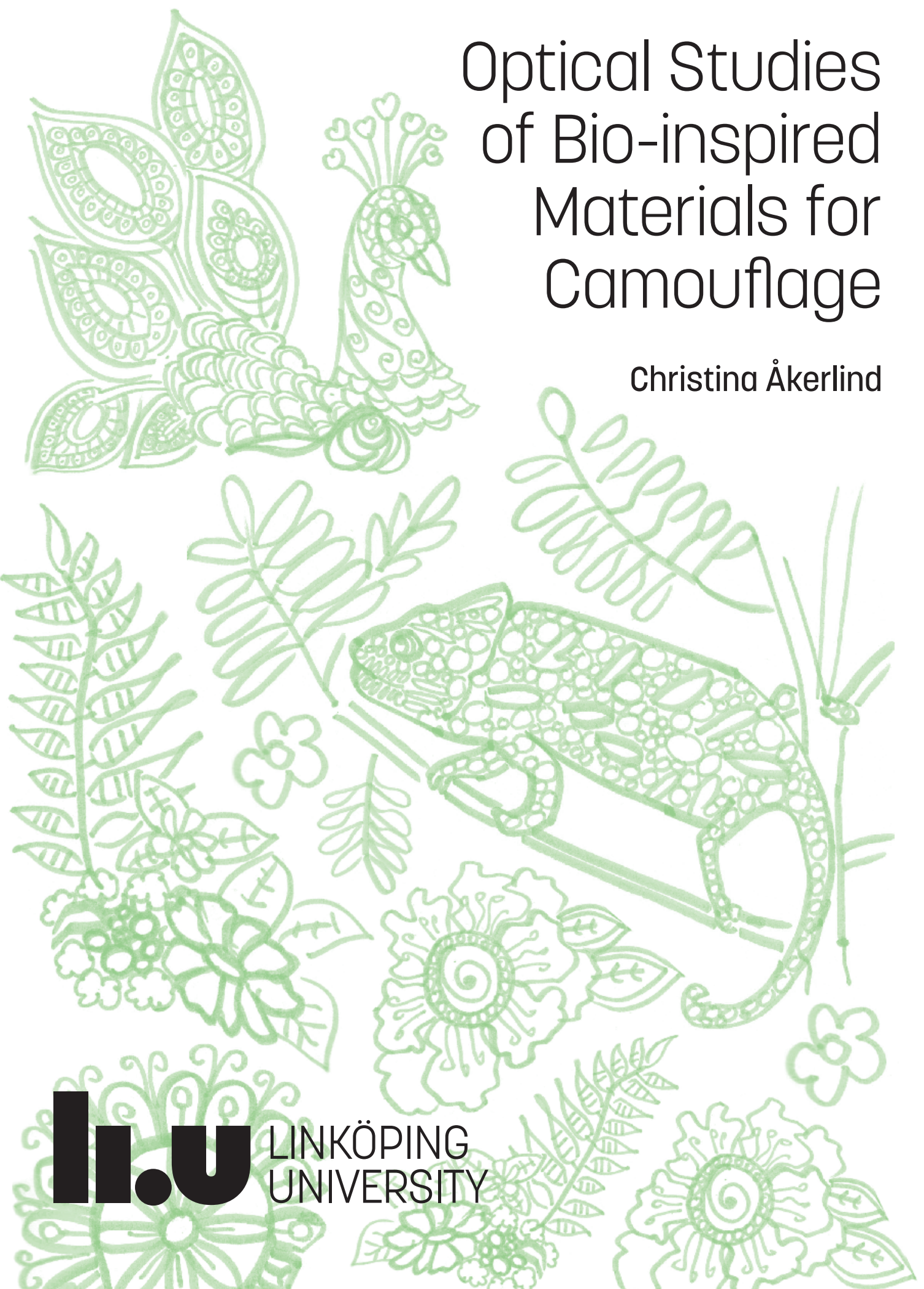




\title{
Optical Studies of Bio-inspired Materials for Camouflage
}

\author{
Christina Åkerlind
}


Cover: Bio-inspired illustrations by Christina Åkerlind

During the course of research underlying this thesis, Christina Åkerlind was enrolled in Agora Materiae and Forum Securitatis, two multidiciplinary doctoral programs at Linköping University, Sweden.

(C) Christina Åkerlind

ISBN 978-91-7929-862-3

ISSN 0345-7524

Printed by LiU-Tryck 2020 
"Peace begins with a smile" — Mother Teresa

TO MY MOTHER

You smiled to me first

for smiles I do thirst

I collect them as treasures,

like pearls on a thread

it is my pleasure

and as someone once said:

for the right kind of smile

I walk the extra mile

I got plenty of smiles that I try to use give me one back please don't refuse once in society smiles become rare it is our duty to smile please do not despair

A smile is simply mighty to reinforce keep that in mind, use yours to endorse one is not dressed without one in mind a smile is a weapon of it's own kind! 

In the ongoing sensor-camouflage duel, new functionalities and sensing abilities are continuously incorporated in detector devices, requiring new capabilities on the camouflage side. The aim of this work is to contribute to improved camouflage including low polarization detectability in wavelength regions with both visible and invisible light. To find new surfaces that can be used as camouflage, we seek for materials that in a spectral design perspective meet the requests of military utility. We have represented this with a 'ladder model' which step by step connects the system and requirements aspects from a basic material level to a useful application.

The focus in this study is mainly on the first rungs of the 'ladder' which are addressing aspects of spectral design and systems engineering as well as requirements of camouflage materials. We have stated six criteria for evaluating camouflage materials and their interactions with light. The criteria are related to reflection, gloss, degree of polarization, emissivity, broadband and dynamic properties.

The included papers can be divided into two parts. The first part is related to aspects of the evaluation criteria for camouflage and the second part presents studies of bio-inspired materials and their performance related to the evaluation criteria.

In connection with the presentation of the 'ladder model' for military utility and the six criteria for camouflage, several materials divided into the four categories: pigments, thin film coatings, multidimensional structures and metamaterials are surveyed. We also studied higher system design levels evaluating the visual and thermal contrast by inspecting images of an object's surface in a background. Important terms and parameters at this level were detectability and the lightness of a color. Furthermore a literature review of polarimetric environmental background properties was performed together with a reference materials study. 
Camouflage properties of several organic material surfaces have been studied. The biopolymeric materials range from beetle cuticle to cellulose based foams and protein fibres. In addition to white structures, we also investigated dynamic properties and initiated work using organic dyes to expand the use of the studied materials to camouflage applications. The main characterization techniques were reflection spectrometry, scatterometry and Mueller-matrix ellipsometry. These methods were used with an aim to mainly investigate the first three camouflage criteria (reflection, gloss, degree of polarization) but also touching on emissivity and dynamic coloring. Overall, the academic approach have been balanced with the requests and limits given by the military utility. The results will contribute to better camouflage by using advanced bio-inspired materials. 


\section{Populärvetenskaplig sammanfattning}

I den pågående duellen mellan sensorer och kamouflage, inkluderas nya funktioner i sensorenheterna, vilket kräver nya funktioner också på kamouflagesidan. Syftet med detta arbete är att bidra till förbättrat kamouflage. Detta inkluderar låg polariseringsgrad för lägre detekterbarhet både i våglängdsområden för synligt och osynligt ljus.

För att hitta nya ytor som kan fungera som kamouflage söker vi material som i ett spektralt designperspektiv uppfyller krav på militär nytta. Vi har representerat detta med en 'stegmodell'. Fokus i denna studie ligger främst på 'stegens' första pinnar som tar upp aspekter av spektral design och systemteknik. Vi har angett sex kriterier för att värdera kamouflagematerial och deras interaktion med ljus. Kriterierna är relaterade till reflektion, glans, polarisationsgrad, emissivitet, bredbandighet och dynamiska egenskaper.

De inkluderade artiklarna kan delas in i två delar. De tre första relaterar till aspekter av kamouflagevärderingskriterier och de tre följande till studier av bioinspirerade material och deras prestanda utifrån värderingskriterierna. 'Stegmodellen' presenteras som ett verktyg för att åstadkomma och bedöma militär nytta vid systemdesign och systemutveckling samt för kravställning. I samma sammanhang introduceras de sex kriterierna för kamouflage och en litteraturstudie görs om material indelade i de fyra kategorierna pigment, tunnfilmsbeläggningar, flerdimensionella strukturer och metamaterial. Vi studerar också högre systemdesignnivåer för att utvärdera den visuella och termiska kontrasten genom att inspektera bilder av en objektyta i en bakgrund. Viktiga termer och parametrar på denna nivå är detekterbarhet och ljushet i färg. Dessutom görs en litteraturgenomgång av polarimetrisk omgivande bakgrund, tillsammans med en kamouflagestudie av referensmaterial.

Kamouflageegenskaper hos flera ytor studeras. Materialen är bioinspirerade och 
sträcker sig från skalbaggevingar till cellulosabaserade skum och proteinfibrer. Förutom vita strukturer har vi även undersökt dynamiska egenskaper samt initierat arbeten med organiska färgämnen för att kunna utöka användningen av våra material till fler kamouflagetillämpningar. De viktigaste karakteriseringsteknikerna som användes var reflektionsspektrometri, skatterometri och Mueller-matris-ellipsometri, huvudsakligen i syfte att undersöka de tre första kamouflagekriterierna reflektion, glans och polarisationsgrad. Också emissivitet och dynamiska egenskaper berörs. Sammantaget har det akademiska tillvägagångssättet balanserats med önskemål och begränsningar som följer av den militära tillämpningen och krav på nytta. Resultaten kommer förhoppningsvis att bidra till bättre kamouflage genom att använda avancerade bioinspirerade material. 
"One can remain more sure-footed by taking small steps, but perhaps achieve greater speed by taking bigger steps. Of course, one also runs the risk of setting out in a completely erroneous direction. Surely the important thing isn't the length of our steps, but that the objective is clear."

— Angela Merkel

This work is a result of a collaboration between the Materials Optics unit (previous Laboratory of Applied Optics) at Thin Film Physics Divison at the Department of Physics, Chemistry and Biology (IFM) at Linköping University (LiU), Sweden, and the Department of Electrooptical Systems ${ }^{1}$ at the C4ISR (Command, Control, Communications, Computers, Intelligence, Surveillance and Reconnaissance) Division, Defence Research Agency (FOI), Linköping, Sweden. The work has been supported by the Swedish Armed Forces through AF.9220419 and the Signature materials project at FOI and the Swedish Government Strategic Research Area in Materials Science on Advanced Functional Materials at Linköping University (Faculty Grant SFO-Mat-LiU No. 2009-00971).

Measurements have been performed at the FOI site in Linköping and at LiU. Part of the results have been presented at conferences in Amsterdam, Toulouse, Warzawa, Paris, Berlin, San Diego, and Barcelona. Camouflage related results are, however, not always easily detected.

\footnotetext{
${ }^{1}$ The author's current affiliation which has varied over the years and the different organization structures at the division.
} 
The thesis is based in part on the Licentiate Thesis ${ }^{2}$. Six papers are included, divided into two themes: criteria of camouflage and bio-inspired materials.

\section{As a Ph.D. student I:}

- have been part of Forum Securitatis, a Doctoral program started by Security Link, an initiative on security as a collaboration between FOI and Linköping University. I have had the opportunity to attend interesting seminars and conferences (Samhällssäkerhet and TAMSEC ${ }^{3}$ ) and got the chance to a broadened perspective of safety and security.

- have been part of Agora Materiae (AFM), a doctoral program started by Advanced Functional Materials, an initiative to strengthen the material research at LiU and also a platform to communicate and integrate the material concept. I was part of the summer school of 2015 planning team with Pitsiri Sukkaew and Zhe Chen, introducing digital poster presentation sessions.

- had the opportunity to take an Ethics course led by Elin Redin and reflect on consequences of research, historical and daily based issues. It was postponed for long, but performed at last and I enjoyed it.

\section{Reflection on Ethics}

My research question in the broad perspective is how camouflage can be improved and protect against detection from polarization sensors specifically. My approach is that we can learn about potential candidate materials and systems by studying natural scattering materials and other similar bio-inspired structures in terms of degree of polarization, reflectance and scattering, i.e. by doing measurements revealing these properties.

By combining materials and structures wisely, the properties of a surface can be designed to spectrally mimic a certain type of environment. When using this, a surface is more difficult to distinguish from the background. - Voilà, you have a camouflage and can provide Swedish military units with increased protection and ability to perform their duties. Provided that the physics, technology and tactics work together optimally, the detection by a sensor can be both hampered and delayed.

My research will add to the common knowledge used for camouflage design, and then it will in the future contribute to help saving life and prolong the time for soldiers to do their duty of defense before they are detected. This is what makes my research important!

\footnotetext{
${ }^{2}$ Optical Studies of Materials for Spectral Design by Christina Åkerlind, Linköping Studies in Science and Technology Thesis No. 1712, IFM, Linköping University, 2015.

${ }^{3}$ Technology and Methodology for Security and Crisis Management, a National symposium managed through Security Link, http://www.security-link.se/.
} 
The ultimate wish would be to contribute to something similar to a Harry Potter invisible cloak ${ }^{4}$, if it ever could be available... An invisibility cloak could in the wrong context or in the hands of enemies, terrorists or criminals do much harm. To avoid a morally problematic use, the Collingridge dilemma ${ }^{5}$ imply that strategies should be made early on for a new technology era to diminish future harm. It is however very hard to foresee which road a technology takes, and how it can be used by creative minds in another context than the inventor had intended.

Ethical codes are set to help and guide researchers. Many ethics codes are about the conducting research ethics, i.e. implement reliability, honesty, respect, and accountability and not accept fabrication, falsification or plagiarism of results for example. ${ }^{6}$ It is good to be reminded also about those elementary things occasionally and to reflect over the fact that we in our work as researchers contribute to the increase of knowledge and we are part of something greater, by serving society, and that society put trust in our work. When thinking of recent and historical examples of when system failure, fraud and fabrication of results have been revealed, we are reminded about how important the personal ethical calibration is. From small issues of concern dealing with the use of scarce money wisely or keep a tidy documentation of your work, to the greater issues of concern, to not tempt to cross the ethical border for a short-term gain of time, money, reputation or what else could be sought for. Often in ethical codes there is a wide statement that researchers should contribute to the general human welfare. The Uppsala Code ${ }^{7}$ has a focus on war and ecological issues. There is a wish that science should not contribute to war and war items. However, in the view of many people, a defense might be needed to promote peace.

When distinguishing between offensive and defensive forces the dilemma of the doubting scientist could possibly be diminished. I see the purpose and usage of camouflage to increase the potential of defense and survivability. If a researcher should not do anything that could be used in war, science would first of all not be where it is today, although some findings are doubtful (for example research during the World War II). All through history, engineers have worked on military solutions, and may be for the greater good for many of us at the end (utilitiarism). Much of the technology that we today take for granted is based on previous military research findings. A few examples: metalworking was early used to provide better spears, arrows and swords but could also be used for tools, art and decorations. The computer and its early precursor calculators, which were originally intended to calculate ballistic trajectories, can today be used in entertainment and visualization. The air tracking radar from 1930's, is today a technique that is

\footnotetext{
4"Harry Potter and the Philosopher's Stone" a fantasy novel written by J. K. Rowling, Bloomsbury, (1997).

${ }^{5}$ The thoughts discussed in the book "The Social Control of Technology" by David Collingridge (1980) have been called the "Collingridge dilemma".

${ }^{6}$ ALLEA, The European Code of Conduct for Research Integrity, (2017), www.allea.org.

${ }^{7}$ Bengt Gustafsson, Lars Rydén, Gunnar Tibell, and Peter Wallensteen, "Focus On: The Uppsala Code of Ethics for Scientist", Journal of Peace Research 21:4, 311-316 (1984); https://doi.org/10.1177/002234338402100401.
} 
also used for traffic control systems and in almost every kitchen equipped with a microwave oven. Internet intended for reliable computer networking in the 1960's, has now become the widespread World Wide Web (WWW) and a source of information. The opposite is often the case today. Common open research of no military connection today will probably be used in something connected to military warfare in the future, although there is no such intent from the beginning. Would that change how we consider open access and the importance of sharing methods and results? If so, our civilization would probably stagnate and we would lack the benefit of utilitarian findings.

Research must be performed in many areas. To present the results openly is part of science. The Uppsala Code ${ }^{7}$ recommend, "free exchange of methods and findings". When it comes to military or industry financed research only general and nonspecific results are possible to publish and present openly. Once findings come to the point that they are not only of general relevance for the Army or the company, they are no longer open to public and will not be published openly. However, my responsibility to my employer is to be cautious with results and data that are of national interest is of higher priority than to the common research community.

The Uppsala Code is rather short and general and needs complementing, as the discussion of Gustafsson ${ }^{7}$ or combined with other codes, such from Vetenskapsrådet ${ }^{8}, \mathrm{EU}^{5}$ or other research specific organizations. There is always the question whether something is done right, or if the right things are done.

\section{What should be done?}

The goal was always to improve camouflage in order to save lives, but how? Sometimes time works for you, sometimes not. Regarding the research material, what should be studied next, and where the focus should be I got great advices from my supervisor(s):

Me: "What you want to do is not always what can be done."

S: "You should not do what you can. One should do things one cannot."

"It is better to start with the almost possible rather than the impossible."

Me: "But what can be done is however not always what you want to do."

S: "The most important is that we are doing really exciting stuff."

"The challenge is to see the new and exciting in what is already known."

As a $\mathrm{PhD}$ dissertation cannot be confidential, although camouflage properties might be, no real camouflage has been studied. Neither has any living animals have been harmed in this study.

\footnotetext{
${ }^{8}$ The Swedish Research Council, http://www.codex.vr.se/forskningsetik.shtml.
} 
I learned through this journey that result matters, but the struggles to find these might be a real treasure hunt. It is possibly easier with a treasure map. Collecting and adding gold grains to a treasure is never wrong, hiding it may be. There was no treasure map and nothing has been intentionally hidden, although work on camouflage is ambiguous in this regard. This is however another story.

"It isn't enough to talk about peace. One must believe in it. And it isn't enough to believe in it. One must work at it."

- Eleanor Roosevelt

\section{Thesis Outline}

Chapter $\mathbf{1}$ is an introduction to camouflage and the theory of signature reduction. Camouflage in a historical (and natural) perspective, and as protection against emerging advanced threat sensors, in a sensor - camouflage duel. Six relevant criteria for camouflage are presented.

Chapter 2 deals with fundamental properties of light (e.g. wave propagation) and the interaction between light and materials (e.g. reflection, transmission, absorption and scattering).

Chapter 3 gives a brief introduction to the origin of color, and discusses vision, perception and detectability.

Chapter 4 gives an introduction to polarization properties.

Chapter 5 gives an introduction to natural camouflage materials and introduces the studied materials.

Chapter 6 contains a brief description of the experimental techniques and the models used.

Chapter 7 summarizes the included papers and presents shortly the findings of this research along with my contributions to them.

Chapter 8 concludes the thesis with a retrospective part and an outlook of future research directions and is followed by the bibliography.

The included papers are found in the last part of the thesis. 



\section{Acknowledgements}

"Titles does not make a man.

But the grace of thanks."

— Lailah Gifty Akita

During my time as a PhD student I was employed at FOI. I would like to thank FOI for the possibility of writing my thesis while working at FOI and the Swedish Armed Forces for funding. My deepest thanks go to all good and kind colleagues through the years, my previous and current office neighbors especially. Thanks to Hans Kariis who knows almost everything, for co-supervising, handling the funding, for sharing his knowledge, and for lending a chair with tolerance whenever I needed to borrow some focus. Thanks to Tomas Hallberg, co-author how luckily is talented in many kinds of measurement techniques, for example spectrometry and scatterometry, for sharing knowledge as well as passion for chocolate. Thanks to Cesar for help with materials and chemical issues, Claes and Carl for nice chats on different subjects. In addition to the 'chewing-gum corridor' mates, thanks to the previous inhabitants of D1:1-3 who were scattered by the wind in different reconstructions, and the Signaturmaterial project members through the years. You know who you are! Thanks to Steven for great advices and Linda H. for kind coaching and valuable technical support. There ain't such as a free lunch, not even free lunch company. Depending on time and whether I go for lunch or lunch came with me, I was always in great company! Thank you Anna, Bengt, Cecilia, Daniel, Hampus, Jacob, Jan, Johan, Julia, Linnea, Magnus, Mårten, Niklas, Nils, Rolf, Sandra, Sebastian, Stefan, Susanne, Sören, Tommy, Åsa and many more that I met for lunch, a coffee in the 'fika'-room or a chatt in a corridor.

I would like to thank Kenneth Järrendahl, my kind supervisor (head of the Materials Optics unit at Thin Film Physics division, LiU) from whom I got my beetle 
(since all students at that time 'ought' to have one), who when entering this abstract and concrete project, did not know that it was almost everlasting. We have seen PhD students come and go. Now an era is over! Thanks to Hans Arwin, co-supervisor and poetry praxis role model for inspiration of complementary documentation methods, and Roger Magnusson, the Ellipsometry Lab 'guard', always cheerful and helpful, for assistance. Thanks to Materials/Applied Opticscolleagues through the years: Iryna, Lia, Samiran, Sergey, Sjoerd, Torun, AnnaMaria, Therese, to name a few and many other kind and helpful people, collegues and collaborators at LiU, IFM and the Thin Film Physics division for a nice and friendly atmosphere. Thanks to co-authors David, Jan, Johan, Fredrik, Niclas, Lei and Sara K for help with measurements, writing and sample preparation, and Korneliya and Lennart at Stockholm University for providing me with foam samples. Thanks to Kent and Carina for sharing the well end woe of PhD-aspirant writing struggles. You showed the way! Thanks to all nice Agora members for a good time at coffee, in seminars, summer schools, study-trips etc. No names, none forgotten! However a special thanks to Lida for always being nice.

Thanks to the friends who remain and who survived work, children, studies and telephone phobia, and the new ones I found during the journey. Thanks to Birgitta and Svenne for the possibility of true vacation without cooking. Mother, Eva and Henrik (and families), thanks for moments of good company through the years, not least the summers together, for support and encouragements and for sharing the love of inspiring words, the vitalizing of thoughts and refreshing smiles.

Thank you Andreas for your love and accompaniment, for sharing life and enduring chaos with me! It is never to late to laugh! Viktoria, for singing your way through life, sharing your patience with me, I need it, and teaching too look for the lost patience in the great joy! Alexander, for a course in wordless communication and an inspiring meet-ball-song ("bob-bulla-la-la") to sing any time. Never stop singing and continue to smile! Thank God it is friday and that I'm done!

Was not your name mentioned? There should have been a long list including many more people. I am sorry I could not express my gratitude fully as words are insufficient.

Colors surround us, from the endless blue sky above us, the fluffy white of clouds, the tranquillizing green of the forests behind, the echoing grey of concrete, and the promising red of raspberries. Colors affect us and so do people and I would like to thank You for coloring my world and work with your shade!

Thank you for your interest and for taking the time to read this!

Christina Akerlind, Linköping, Sweden, a raspberry-day in September 2020, in times otherwise marked by distance, Covid-19 and Corona. 
1 Introduction and Background 1

1.1 Signature, Camouflage and Environment . . . . . . . . . . . . 1

1.2 Purpose and Motivation of this Study . . . . . . . . . . . 7

2 Interaction of Light and Matter 9

2.1 The Nature of Light . . . . . . . . . . . . . . . . . . . 9 9

2.2 Light and Matter Interaction . . . . . . . . . . . . . 10

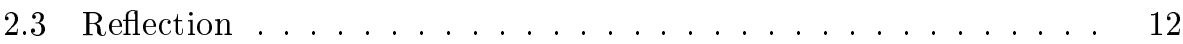

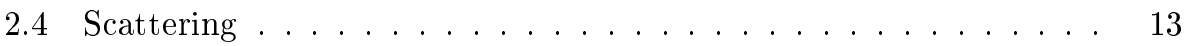

2.5 Emission and Absorption ................. 14

3 Color Perspective 17

3.1 Colors from a Sensing Perspective . . . . . . . . . . . . . 17

3.2 Colors from a Materials Perspective . . . . . . . . . . . . . 18

3.3 Chromism and Examples of Adaptivity . . . . . . . . . . . 20

3.4 Color Coordinates . . . . . . . . . . . . . . . 21

4 Optical Polarization $\mathbf{2 5}$

4.1 Polarization of Light . . . . . . . . . . . . . . . 25

4.2 Stokes-Mueller formalism . . . . . . . . . . . . . . . . 27

4.3 Polarization and Camouflage . . . . . . . . . . . . 29

5 Materials 31

5.1 Camouflage Materials in Nature . . . . . . . . . . . . . . 31

5.2 Materials in this Study . . . . . . . . . . . . . . . 32

5.2.1 Background Reference Materials . . . . . . . . . . 32

5.2 .2 Biopolymers................. 33 
6 Methods $\quad 37$

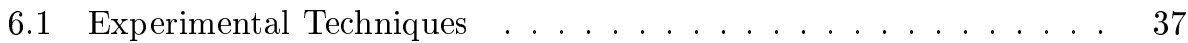

6.2 Calculations and Modeling. . . . . . . . . . . . . . . . 42

6.2.1 Optical Modeling . . . . . . . . . . . . . 42

6.2.2 Other Modeling Software ............. . 44

7 Summary of Included Papers and My Contribution 47

7.1 List of Papers and My Contributions . . . . . . . . . . . . . . 47

7.1.1 Evaluation Criteria for Camouflage . . . . . . . . . . . 47

7.1.2 Studies of Bio-Inspired Materials . . . . . . . . . . 48

7.2 Results ......................... 48

7.3 Papers not Included in this Thesis . . . . . . . . . . 51

8 Conclusions and Outlook $\mathbf{5 3}$

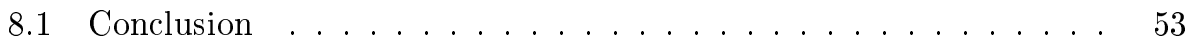

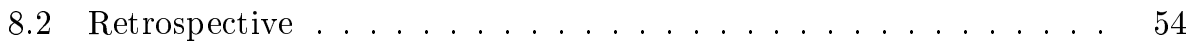

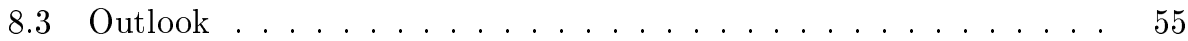

$\begin{array}{ll}\text { Bibliography } & 59\end{array}$

Paper I

Paper II

Paper III

Paper IV

Paper V

Paper VI

A Abbreviations

B Terminology

C Applied poetry

D Whom to quote 


\section{CHAPTER 1}

\section{Introduction and Background}

"Courage is the ladder on which all the other virtues mount."

- Clare Boothe Luce

In this first chapter the concept of signature reduction and camouflage is explained briefly and an introduction to the six criteria of camouflage is given, followed by a description of the environment for which they are aimed. This chapter encloses the motivation of this study: 'If they don't see you, they can't shoot you.'

\subsection{Signature, Camouflage and Environment}

'If they can't see you, they can't shoot you!' To survive you either stay out of sight, far away, or you use some kind of camouflage to lower your signature, and can stay unseen at a closer distance. The meaning of the word signature is that something has a feature that can be recognized to identify that something; a melody, a person, a vehicle, etc. To be recognized is of importance for many reasons. In some situations the urge is the opposite. In history of war, kings or emperors have come up with the idea that if we dress in rich, bright colors and use loud drums and make a lot of noise, i.e. use a high signature, they should be recognized as strong and impressive and thereby discourage and maybe also frighten the enemy. It did not always turn out well and that tactic is more or less abondoned.

In a military context signature reduction has instead become common. That is, to hide or conceal an object to adapt to the environmental background and thereby stay unrecognized. Often it is a question about lowering the contrast between the object and the surrounding background. The art and techniques of altering 
a signature in one way or another is called signature management and the way of doing it is through the use of signature management techniques (SAT) ${ }^{1}$. An example is the use of camouflage nets, as illustrated in Fig.1.1.

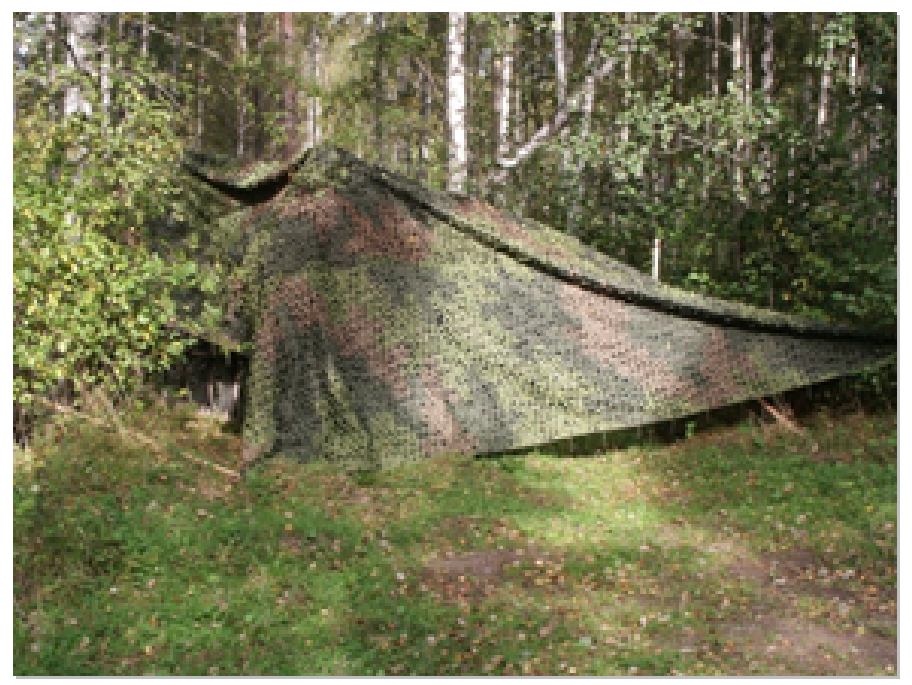

Figure 1.1. An example of a camouflage net, (CFOI.

Camouflage as a concept has always been important, e.g. in nature when a prey hides from predators. Each specimen has its own kind of characteristics (dots, stripes etc.) suitable for protection in its domain and principles of living [1].

For humans in the roles as soldiers, using SAT or as hunters (or robbers), camouflage is important. Gray, black, brown and green colors have proved to be an efficient survival concept over the last hundred years for soldiers, vehicles and nets etc., adapting well to the basic colors of nature which represented in Fig.1.2.

During World War I, experiments were performed with disruptive patterns [3, 2]. At that time, systems were painted in dots and stripes by artists aiming at an elusive scene and to contribute to the common deception. The colors and striped patterns at that time, used in attempts to deceive and mislead, has the same goal today, but are refined to better match the surrounding nature.

There is a reawoken interest to seek help from nature to solve problems of humanity. Biomimetics ${ }^{2}$ is the art of learning from nature to solve engineering problems in a smart way, and here also camouflage aspects are included. During the last decade several findings related to animal and camouflage has enriched science. The stripes of the zebra were for long thought of as a disruptive camouflage pattern.

\footnotetext{
${ }^{1}$ SAT originates from the Swedish wording 'signaturanpassningsteknik'.

${ }^{2}$ In the nomenclature biomimetics, bio-synthetics and bioionics etc. can be included.
} 


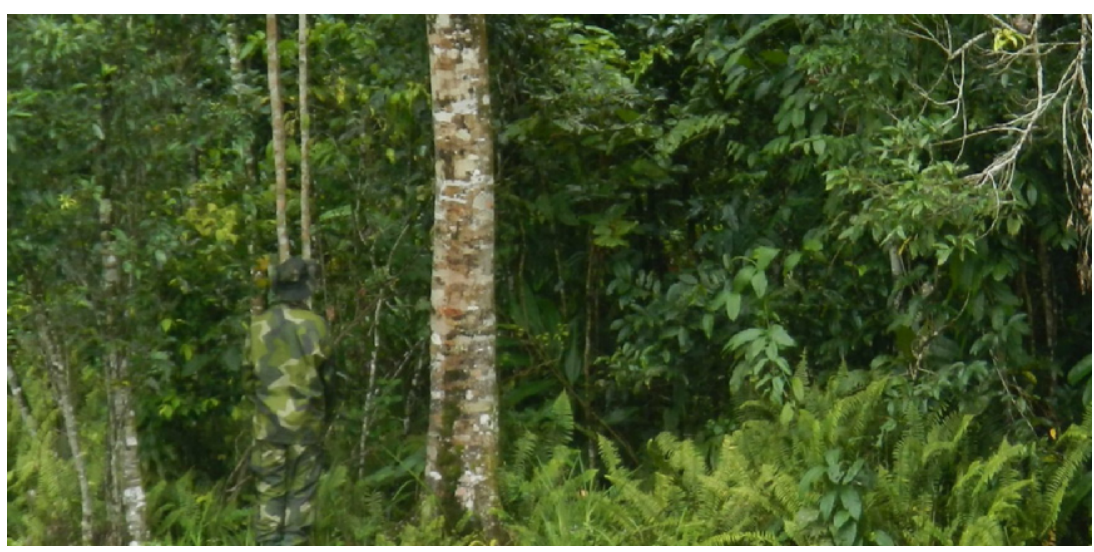

Figure 1.2. An example of a background, CFOI.

Now it has been shown that they have an extraordinary purpose, different from the camouflage aspect, which for a long time was hidden to human knowledge. The stripes are used for the confusion of bugs and flies from a polarization view perspective. Another example of this are white horses which are less attractive to polarization sensitive flies than black horses [4]. This is due to the polarization sensitive eyes of these insects making them detect the latter type of horse showing a stronger polarization pattern. Polarization sensitivity is implemented in modern sensor technology and is ready to use for reconnaissance and detection based on polarization features.

New functionalities and sensing abilities are developed and implemented in recent sensor versions. This requires new capabilities also on the camouflage side. To hide from these kinds of sensors, new concepts of deceiving and concealing camouflage are desired, in addition to the commonly used tactic strategies or surprising trick of not being there. The camouflage techniques are always on a duelling stride with the sensors. Therefore, the camouflage materials must develop in a more clever way to stay hidden also in the future.

Everybody with normal vision is familiar with the basic colors of the natural environment. Nature also varies with, for instance, season and humidity. To adapt to the environmental background in the visible range, the color match is of importance but the properties in the infrared (IR) range are not common knowledge. Often a clear sky and the nature at cold conditions appear 'black' in an IR sensor ${ }^{3}$. A hot object on the other hand appears rather bright. One way of adaption is to coat the high temperatured parts with low emissive material. Then these surfaces will give the same emission as the 'black' nature and the surface will appear cooler

\footnotetext{
${ }^{3}$ The appearance of 'black' or 'white' in gray scale is dependent on the settings in the sensor and may be switched.
} 
than it is.

The nature surrounding us, the environmental background, reflects light that is unpolarized to a great extent also if the incident light is polarized. Flat surfaces often reflects polarized light, especially near the Brewster angle. The number of flat surfaces in nature are, however, limited. There are exceptions, of course, such as water surfaces. Other examples are the sky [5], and exoskeletons of some beetles [6, 7]. Man-made surfaces, however, often appear to have specific polarization properties. Considering this fact, it would be clever to think once or twice about the depolarizing response from surfaces to see if they adapt well into nature. Our approach and hypothesis are that an effective camouflage against detection by polarization sensitive cameras would need to have depolarizing properties. Thus the reflected beam should be unpolarized to a high extent, also if the incident beam is polarized.

The polarization properties are only a part of the total sensor information. Many other characteristics must be counted on regarding a sensor threat (and a working system): atmospheric transmission, the environmental background properties, position of target relataive to threatening sensors and radiation sources, etc, as illustrated in Fig.1.3.

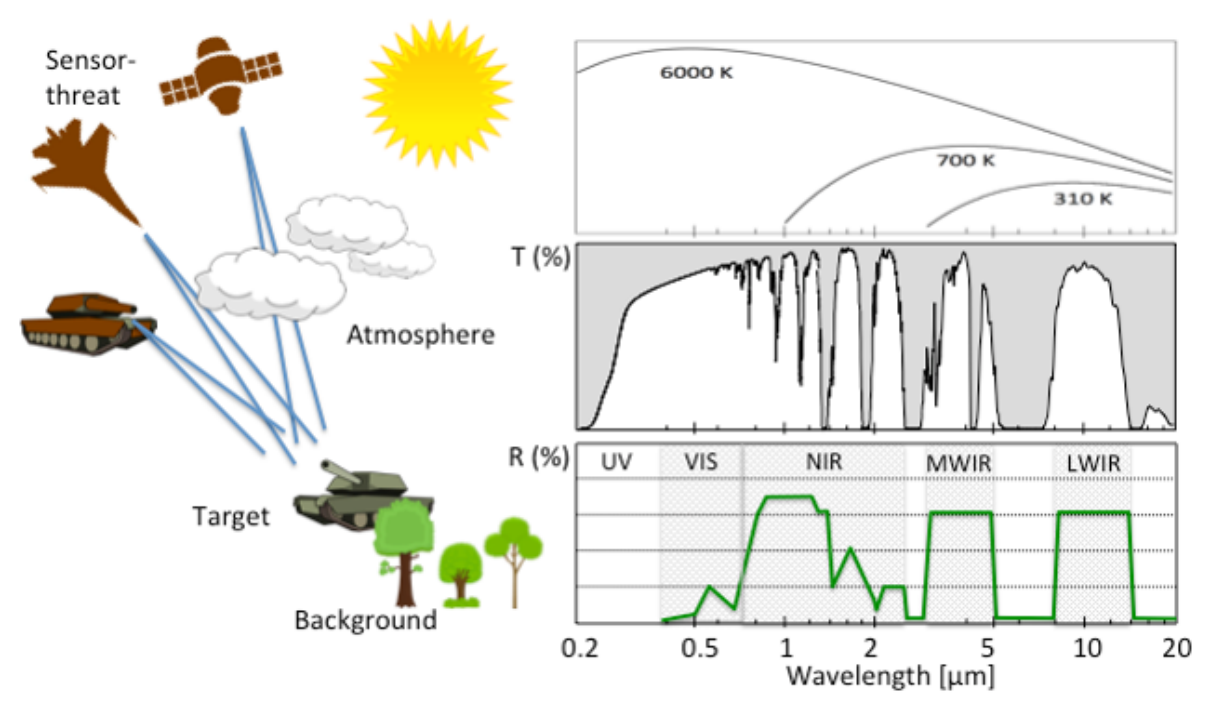

Figure 1.3. The sensor threat is depending on the lighting conditions, atmospheric transmission, the background and position relative to the target. Here the energy content of the sun, transmission of the atmosphere and an estimate of wanted reflectance properties of a camouflage are represented as a function of wavelenght, respectively. [8] Reprinted with permission, (C)2020 SPIE. 
A modern theory of camouflage properties, propose that there are six important criteria of concern in the design of a camouflage [8]:

1. spectrally selective reflectance

2. low gloss

3. low degree of polarization

4. low infrared emissivity

5. broad-band properties (including non-destructive effect on radar properties)

6. color adaptivity

The first four criteria are more or less features of optical properties achieved by structure and material design. These properties are often interrelated. For example, both low gloss and low degree of polarization origin from a rough surface. There is however no contradiction in this. In the choice of materials combinations, layer thicknesess and surface conditions, all the six criteria can be tailored. Also reflectance and emissivity are related in IR.

For every situation the perfect background adaption requires specialised camouflage system and color. Also in the best of worlds, resources are scarce so priorities and compromises must be made. An all time perfect match is perhaps not what is wanted after all. Better is an affordable 'good enough' fit to a general environmental background type, that is suitable for the user to perform the task.

The choice of materials, based on our elements and combination of these to produce an object, tool or other item, determines what final properties the product can have. In other words, the material properties of these selected materials are of great importance for the properties and usefulness of the final product. To illustrate how the materials and surface properties impact the military utility, the 'ladder model' is introduced [8]. Here each yellow rung symbolizes a property which is used in the white rung, symbolizing an action taken at a system level. Several rungs are needed to connect the spectral design properties at a material level, with the final military utility and task performance level. The requirements at the military utility system level is dependent also on the camouflage criteria. From the other perspective, the choise of materials at the fundamental material level, sets the base for the spectral design and signature properties in a system view. Most of this work is related to the intermediate levels or those next to system engineering and spectral design, i.e. object signatures and surface structure properties, as shown in Fig.1.4.

What does the environmental background look like, to which objects must adapt? Is there at all a general background? In [8] we suggest certain values in different wavelength regions, as account must be taken to, when evaluating a sensor threat. Basics of importance are lighting conditions, transmission of atmosphere, chlorophyll absorption and reflection in relation to the camouflage and the environment, 


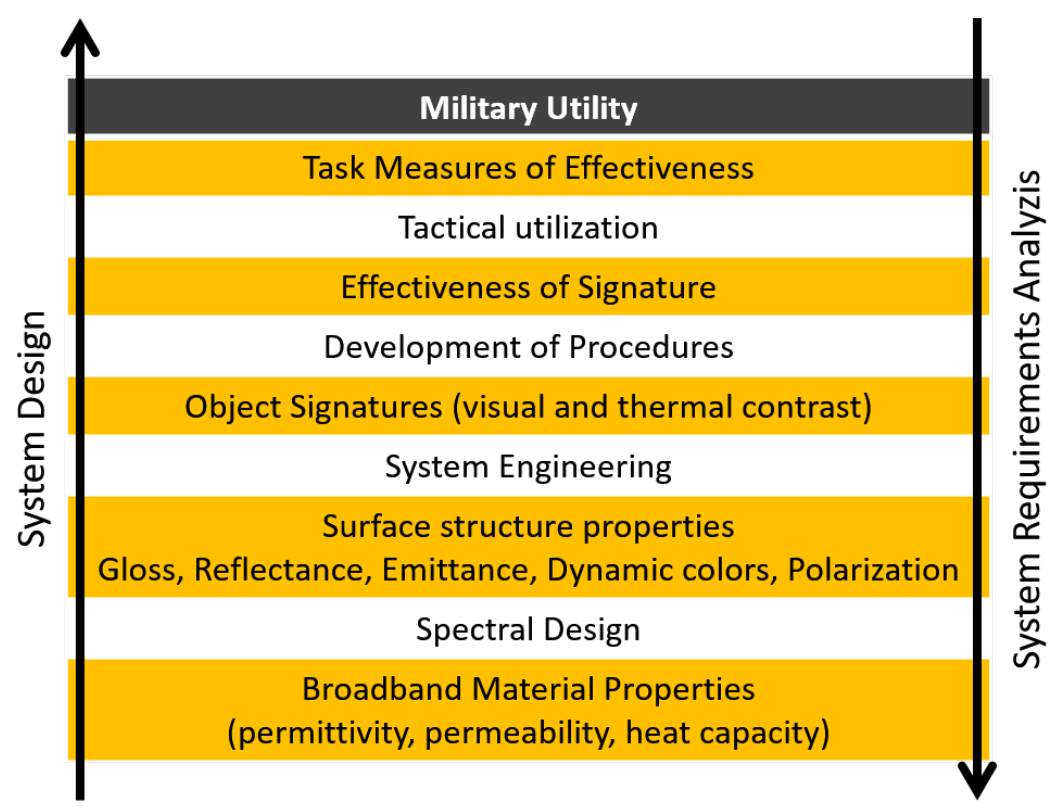

Figure 1.4. The 'ladder model', a model that step-wise connects the fundamental material properties, a key-step in system design, with the final purpose of military utility of a system in use. And vice versa, an analytic process to determine what system requirements are needed at each level to finally have a good-enough system. The yellow rungs relate to fundamental material or surface properties in different aspects. The white rungs relate to actions taken at a system level. Reprinted (PAPER II) with permission. (C) 2020 SPIE.

as well as blackbody radiation, as is illustrated in Fig.1.3. Although important and of high concern in materials characterisation and in the early development phase, other parameters will take over in the next system engineering level, as illustrated in Fig.1.4. Reflection is a surface characteristic. In a camouflage context contrast and detectability are important parameters. These are, however, not straight forward to measure. Contrast is always considered between a surface or an object and the background. Detectability, either in distance or in time, is a measure of how good or bad the camouflage is. It also reveals how well the object blends into the background. In the visible range color and especially lightess play important roles. Temperature is of high importance in IR. A hot body in a hot climate will not give a great contrast. The radiated intensity, and thereby the ability of detection, is then dependent on an object temperature, size, emissivity and the distance between sensor and object. In IR low emissivity can have a role to play. A low-emissive surface has a lower apparent temperature than the original surface (PAPER II). The 'ladder model' does not include any other aspects than those related to spectral or signature issues. Other material properties and system 
requirements such as robustness, strength and weight are of course of great importance but are not covered here. To enable camouflage also in urban environment, which is important for military operations, optical properties of some non-natural materials have been studied, as background reference materials. However, to better hide in a natural background, natural based materials are proposed to be used. For sustainability and better performance, systematic modifications step by step might be needed, as well as ideas and inspiration elected and used from diversified fields.

\subsection{Purpose and Motivation of this Study}

The purpose of this study is to take inspiration from nature and biomimetics to search for future (bio-inspired) camouflage materials candidates that possibly could fulfill the camouflage criteria described in the previous section.

In this work, we mainly address the most optics-related criteria (1-4) by measuring reflectance, scattering (gloss) and polarization properties. We are however, also touching upon the adaptivity criteria (6) in a few cases.

New polarimetric and hyperspectral sensors demand improved camouflage. As man-made surfaces often appear to be highly polarized, new depolarizing materials could be sought for in nature among natural or bio-inspired materials or through biomimetics.

The white beetle Cyphochilus insulanus scatters white light exceptionally well despite its thin shell [10] and was used as an introductory material in our studies. Surface and systems modifications needed from perspectives other than optical are not considered in this study. 


\title{
CHAPTER 2
}

\section{Interaction of Light and Matter}

\author{
"Science and everyday life \\ cannot and should not \\ be separated."
}

— Rosalind Franklin

In this chapter all light is on light and how light interacts with matter resulting in reflection, scattering, transmission and absorption and enlightenment.

\subsection{The Nature of Light}

Light is electromagnetic radiation. Sometimes in physics, electromagnetic radiation of any wavelength is called light, but we as humans can only see a small part of the spectrum. Different classifications are made and different terminologies are given according to wavelength: radio waves, microwaves (radar), infrared (IR), visible (VIS), ultraviolet (UV), X-rays and gamma rays, as illustrated in Fig.2.1.

In this thesis I mainly refer to the visible and infrared part of the wavelength spectrum, although also microwaves, or commonly radar, are of importance in camouflage applications. Important properties of light are intensity, direction, wavelength or frequency and polarization. The wavelength determines the photon energy and behaviors in many aspects. E.g. light interaction with matter is wavelength dependent.

Human eyes can see in the visible range, approximately corresponding to wavelengths between 380 and $780 \mathrm{~nm}$. Other natural sensors, such as the eyes of insects and birds, are in addition often sensitive to UV light. Some snakes have beside 


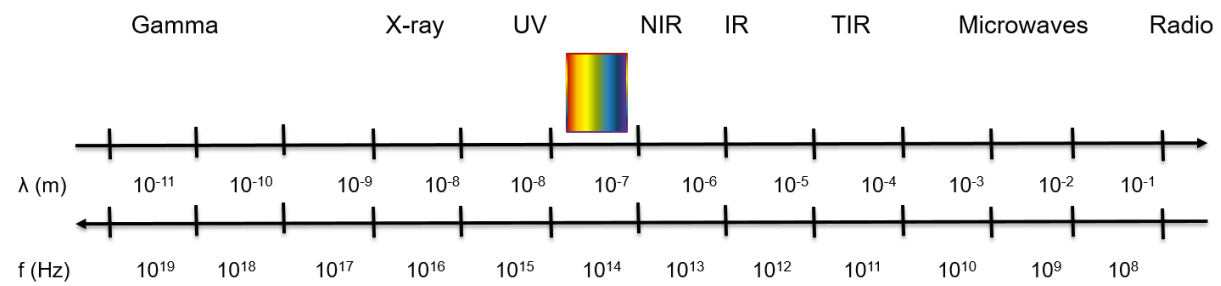

Figure 2.1. The electromagnetic spectrum of which the light visible to humans, approximately $380-780 \mathrm{~nm}$, is only a small part. Short wavelengths $(\lambda)$ corresponds to high frequencies $(f)$.

their eyes additional organs with sensitivity towards thermal infrared (TIR) radiation [11]. Artificial sensors can be made to have sensitivity in different ranges, depending on the materials used. Sensor materials and compositions are continously being developed.

\subsection{Light and Matter Interaction}

A light wave can interact with matter in different ways which are illustrated in Fig.2.2. This interaction depends on the wavelengths of the light, the temperature and on the material and its surface and bulk properties. The light can be either transmitted (go through the medium), reflected (specularly as in a mirror, or diffusely scattered), or absorbed. When absorbed, the material is heated up by the energy of the radiation and this often results in emission, sometimes at another wavelength. A combination of these phenomena is also possible.

To describe light, Maxwell's equations [12, 13] provide the fundamental relations. The same theory can then be applied to describe wave propagation phenomena at any wavelength, which is convenient. Through Maxwell's equations, field or wave properties of light can be related to specific material properties, such as $\epsilon$, $\mu$ and $\sigma$, the permittivity, permeability and the conductivity, respectively. ${ }^{4}$ Often the conductivity is included in the dielectric function $(\epsilon)$, which is the case here.

Sometimes the entities $\epsilon_{1}$ and $\epsilon_{2}$ are used instead [14, 15]. They represent the real and imaginary part of $\epsilon=\epsilon_{1}+i \epsilon_{2}$ and are connected through the KramersKronig relations. The complex-valued refractive index $N$ is often convenient to use when discussing the context of materials and their optical properties. The relation between $N$ and $\epsilon$ is given by

$$
N=\sqrt{\epsilon}
$$

\footnotetext{
${ }^{4}$ The permittivity is often called the dielectric function, when a function of frequency and space. Permeability is related to magnetic properties, for all materials in this study these are neglectable at optical frequencies.
} 


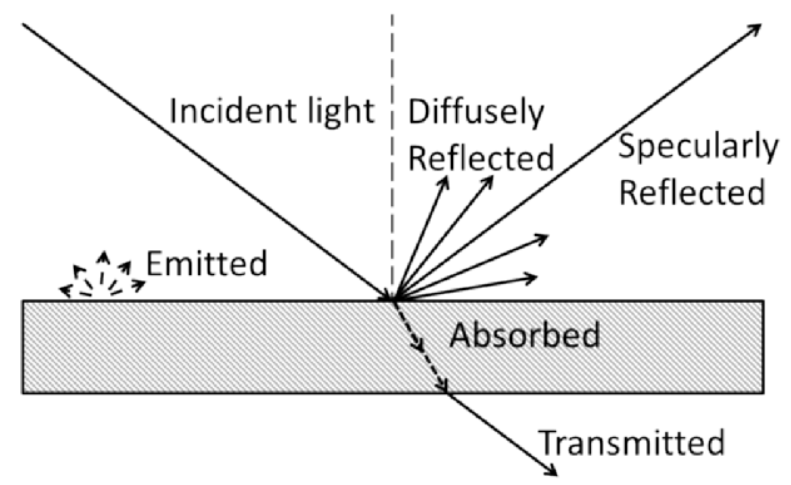

Figure 2.2. Light and material interactions: transmission, reflection, scattering, absorption and emission.

In optics it is often sufficient to use $N=n+i k$. Here $n$ is the real part describing refraction, whereas $k$ is the imaginary part, also called the extinction coefficient. The absorption coefficient $\alpha$ is connected to $k$ through $\alpha=4 \pi k / \lambda$.

Two orthogonal components are enough to describe the electric field $\mathbf{E}$ of a plane wave traveling in direction $\hat{\mathbf{z}}$ in an $x y z$-coordinate system. If $\mathbf{E}(z, t)$ is the plane wave, then the total $\mathbf{E}$-field is described by the $E_{x}(z, t)$ and $E_{y}(z, t)$ components:

$$
\begin{aligned}
\mathbf{E}(z, t) & =E_{x}(z, t) \hat{\mathbf{x}}+E_{y}(z, t) \hat{\mathbf{y}} \\
& =E_{x}(t) \cos \left(q z-\omega t+\delta_{x}(t)\right) \hat{\mathbf{x}}+E_{y}(t) \cos \left(q z-\omega t+\delta_{y}(t)\right) \hat{\mathbf{y}}
\end{aligned}
$$

Here $E_{x}(t)$ and $E_{y}(t)$ are amplitudes in the $x$ - and $y$-directions, with a phase difference, $\delta(t)=\delta_{y}(t)-\delta_{x}(t)$, between the $\mathbf{E}$-field components and $q$ is the wave vector. One of the components is often chosen to be parallel (denoted $p$ ) to the plane of incidence. The other component is then perpendicular (denoted $s^{5}$ ) to the plane, as seen in Fig.2.4. Here the plane of the paper/screen coincides with the plane of incidence. The $s$ and $p$ components indicate the different polarization directions. Thus, in the setup of Fig.2.4, the $p$-polarized electric field $E_{p}$ is oscillating in the plane of the paper, and the $s$-polarized field $E_{s}$ is oscillating perpendicular to the plane of the paper.

Polarization defines how the electric field of the beam is orientated in relation to its propagation. In the interaction with materials, the phase and amplitude of the electric field can change in different ways, depending on the optical properties and structure of the interacting material. Polarization is described in more detail in Chapter 4 .

\footnotetext{
${ }^{5} s$ from the German word senkrecht for perpendicular, and $p$ from the German word parallel for parallel.
} 


\section{$2.3 \quad$ Reflection}

As mentioned above, reflections can be either specular or non-specular (diffusively scattered) or a combination of these as illustrated in Fig.2.3.

a)

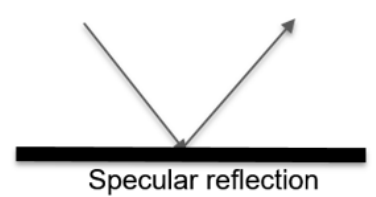

b)

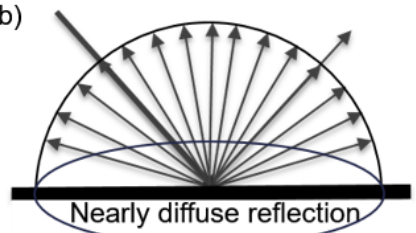

c)

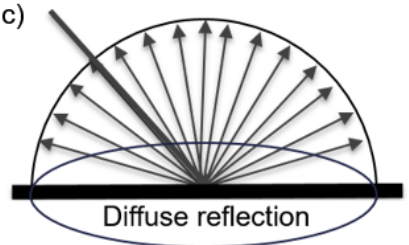

Figure 2.3. a) Light can be specularly reflected (mirror reflection), c) ideally diffusely reflected (Lambertian scattering) or schematically shown in b) a combination of these.

When describing specular reflection from a smooth (glossy) surface, i.e. a mirror, Fresnel's reflection equations (2.3 and 2.4) are useful [13]. They provide the amplitude reflection coefficients according to

$$
\begin{aligned}
& r_{p}=\left(E_{0 r p} / E_{0 i p}\right)=\left(n_{t} \cos \theta_{i}-n_{i} \cos \theta_{t}\right) /\left(n_{t} \cos \theta_{i}+n_{i} \cos \theta_{t}\right) \\
& r_{s}=\left(E_{0 r s} / E_{0 i s}\right)=\left(n_{i} \cos \theta_{i}-n_{t} \cos \theta_{t}\right) /\left(n_{i} \cos \theta_{i}+n_{t} \cos \theta_{t}\right)
\end{aligned}
$$

The reflected amplitudes of the incident and reflected fields at the boundary, $E_{0 i}$ and $E_{0 r}$ respectively, are divided into a $p$ and $s$ polarized part as described in Eq.2.3 and 2.4 above. $n_{i}$ and $n_{t}$ are the refractive indices as shown in Fig.2.4. In the case of reflection, the incident angle $\theta_{i}$ equals the angle of reflection $\theta_{r}$, while $\theta_{t}$ is the angle of refraction after transmission, as illustrated in Fig.2.4.

The Fresnel's reflection coefficients $r_{p}$ and $r_{s}$ relate to the reflectances $R_{p}$ and $R_{s}$ according to,

$$
\begin{aligned}
& R_{p}=\left|r_{p}\right|^{2}=\left(\left|E_{0 r p}\right| /\left|E_{0 i p}\right|\right)^{2} \\
& R_{s}=\left|r_{s}\right|^{2}=\left(\left|E_{0 r s}\right| /\left|E_{0 i s}\right|\right)^{2}
\end{aligned}
$$

We can also express the reflectance $R$, defined as the ratio between the reflected power (flux) and the incident power (flux), or as the ratio between the reflected and incident irradiance $\left(R=I_{r} / I_{i}\right)$. The transmittance $T$ can in a similar way be described with the ratio between the transmitted and incident irradiance.

When light is reflected from a sample consisting of a thin film at a substrate, interference can occur. The light directly reflected from the first surface, travels a different optical distance (optical path length) compared to the light first transmitted, refracted and then reflected in the second surface. In this way the light reflected from the sample is a combination of rays that superimpose, causing constructive or destructive interference depending on the angle of the incident beam $\left(\theta_{i}\right)$, the wavelenght $(\lambda)$, the refractive index $(n)$ of the medium and the thickness $(d)$ of the film. 


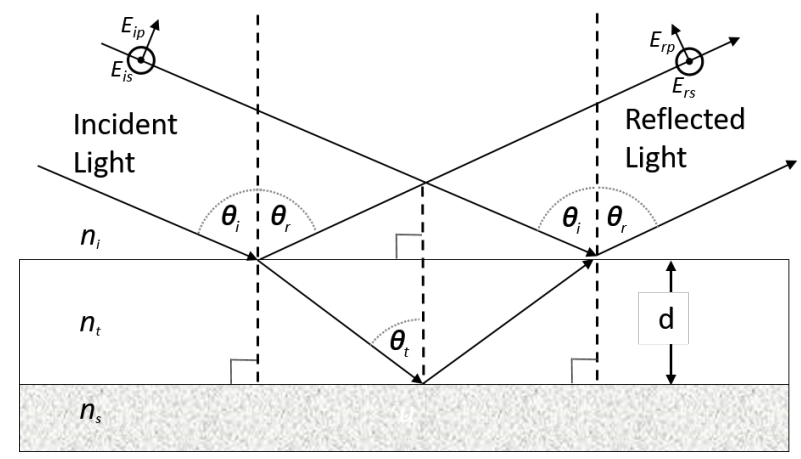

Figure 2.4. Reflection of a plane wave on a thin film surface. The film thickness $d$, and the refractive index $n$ determine the light's path through the medium. In the case of specular reflection, $\theta_{i}=\theta_{r}$.

\subsection{Scattering}

A rough surface, i.e. not smooth or glossy, will reflect the light in different directions. The reflection is then called diffuse. These properties are wavelength dependent. Smoothness or roughness are thereby surface properties which will have different influence depending on the interacting wavelength. A surface can be considered rough in some cases and smooth in other, for example in different wavelengths regions as VIS and IR. Diffusely reflected is spread in many directions as can be seen in Fig.2.3.

In addition to light reflected from rough surfaces scattering can, for example, be studied by looking up into the sky where the sunlight on its propagation through the atmosphere is scattered by the large amount of particles in the air. Of importance here is the wavelength, the surface roughness or size and concentration of the interacting particles in the air. The combination determines what type of scattering that occurs. Often three different categories of scattering are considered, determined by the structure size $(\phi)$ compared to the wavelength $(\lambda)$.

Rayleigh scattering occure when the particles or structures are smaller than the interacting wavelengths of light $(\phi<\lambda)[16]$. An example is sunlight scattered by the atmosphere, causing a diffusely radiating blue sky. The short blue wavelenghts are scattered more efficiently by the atmosphere than longer wavelengths, and thereby coloring the sky blue.

Mie scattering occure when the interacting wavelengths and particles are of comparable dimensions $(\phi \approx \lambda)[16]$. An example is clouds appearing white, since visible light is interacting with water droplets (in the cloud) of the same size as the wavelength.

When the interfering particles size is of dimensions greater than the interacting 
light $(\phi>\lambda)$, other more complex models are desired.

A concept of importance in the context of diffuse scattering is the Lambertian [17] surface $^{6}$. This is a theoretical surface that is ideally diffusely reflecting. This means that the light is scattered equally at all angles. The Lambert's cosine law as described in Eq.2.7 is thereby fulfilled.

$$
I(\theta)=I_{0} \cos \theta
$$

Lambert's cosine law states that the emitted or reflected irradiance $I(\theta)$, at the angle $\theta$ from the surface normal, is proportional to the $\cos \theta$ and the incident irradiance in the normal direction $I_{0}$. Diffuse scattering properties such as for a Lambertian surface are obtained due to surface roughness often combined with bulk scattering. Bulk scattering defined as light that has entered into the bulk material, and after multiple scattering inside the bulk eventually is reflected back through the surface. Scattering properties are wavelength dependent. This means that a surface might scatter IR wavelengths according to the Mie theory. Longer wavelengths, e.g. microwaves, may instead be subject to Rayleigh scattering. A surface with Lambertian properties in the visible, is not with necessity a Lambertian scatterer at other wavelengths. Worth mentioning is that no ideal Lambertian surfaces exist in reality. Even surfaces close to Lambertian properties are rare in nature. In Chapter 6 Lambertian properties are discussed further.

\subsection{Emission and Absorption}

The part of the radiation incoming at a surface, which is not reflected with reflectance $R$ or transmitted with transmittance $T$, will be absorbed and can be specified with the absorptance $A$. As conservation of energy rules, the relation $R+T+A=1$ is valid. Emissivity $\epsilon_{m}$ is a measure of the thermal behaviour of a material, or in other words, an optical property holding information about how much the material will emit energy. Low emissivity $\epsilon_{m}$ in TIR is considered to be one of the camouflage criteria. In specific conditions $(T=0)$ and assuming geometrical and spectral averaging [18], the emissivity equals the absorptance $A$, $\epsilon_{m}=A$.

The more reflective an opaque $(T=0)$ material is, the lower is the emissivity. Emissivity is both angle and wavelength dependent. It can be expressed as a ratio between the energy emitted from an objects surface $\left(\epsilon_{m}<1\right)$, to the energy emitted by a perfect blackbody $\left(\epsilon_{m}=1\right)$, when the surfaces have the same temperature. According to Boltzmann's law [19], all objects or bodies emit blackbody radiation determined by its temperature. A $20^{\circ} \mathrm{C}$ tempered body will emit radiation in TIR and will peak at a wavelength of $10 \mu \mathrm{m}$. The atmosphere is highly transmitting at this wavelength. IR sensors can thereby easily be used also at long distances with the consequence of high detectability for objects that have a

\footnotetext{
${ }^{6}$ Johann Heinrich Lambert was a Swiss polymath, a Renaissance man, educated in many subjects. In his book Photometria (1760) he presented the idea of perfect diffusion.
} 
temperature contrast against the background.

Absorption can be discussed from different aspects. The chemical bonds between atoms and molecules vibrate at specific wavelengths and can be observed when energy is absorbed or emitted. These vibration modes are compound characteristic [20]. A specific chemical 'fingerprint' is then achieved for each compound from the combination of the absorption resonance peaks that can be deciphered through for example spectroscopic reflectance measurements. The absorption peaks of water together with absorption of carbon dioxide at ca. $4.25 \mu \mathrm{m}$ are the primarily cause of the limitation of atmosphereic transmission. The long-range performance of sensors are thereby constrained to certain wavelength bands often referred to as the mid-wave (MWIR) and long-wave infrared (LWIR) regions, $3-5 \mu \mathrm{m}$ and 8$12 \mu \mathrm{m}$, respectively [21]. Also when coloring or pigmenting a surface, absorption plays an important part. The color of a material is due to that light in certain wavelength ranges are reflected, while absorbed or transmitted in other regions. In addition, the perceived color often differs when viewed in reflection compared to transmission. 


\title{
CHAPTER 3
}

Color Perspective

\author{
"Happiness can be found, \\ even in the darkest of times, \\ if one only remembers \\ to turn on the light." \\ - J. K. Rowling, Harry Potter and \\ the Prisoner of Azkaban
}

In this chapter different perspectives of colors are described, such as from a sensing (vision, perception and sensors) and materials (structural colors, pigment and chromic) view. Additionally different kinds of color coordinate systems are described. Colors are not defined outside the visible region. A spectral selectivity recognized in the infrared region, can be considered as a generalization of the term color.

\subsection{Colors from a Sensing Perspective}

The colors of objects surrounding us is not solely due to materials properties, but also involves illumination and sensing of light. The light reflected or transmitted by an object, causes a perception in our brain through stimulation of the retina of the eyes. If no light, there is no color [22].

Human eyes are equipped with photoreceptors called cones and rods. Cones of three different kinds are sensitive to light of different wavelengths, but do not respond at low levels of light. The rods are rather photosensitive and can react to light from a single photon, i.e. also at low light intensities. The rods are however monochrome [23]. A combination of red, green and blue light is recognized as 
white light by the eye. The colors that the eyes see are not necessarily spectrally the same as can be measured by a spectrometer.

Different from vision and the ability to see is perception. We then not only refer to ability of receiving signals but also the processes in which basic signals are transformed to high level information in the brain. Examples are the ability to extract information about shapes and object recognition and the process involving the learning memory, expectation and attention. These abilities are to some extent unconscious and depend on complex functions of the nervous system and depend to some extent on training and experience. Perception is an important ability in the context of evaluating colors of camouflage and its detectability in a background as discussed in PAPER II.

Sensors in the visible range other than eye are often based on a silicon detector element. Thermal sensors have been used since Herschel's experiment [24, 25] with a thermometer in the year 1800. An IR detector is sensitive to the emitted radiation of an object. It can for example register temperature differences between a hot object and a cold background. The sensitivity range of the used material is based on the so called band-gap and must correspond to the photon energy of the wavelength to be detected. In the near infrared range, combinations of gallium $(\mathrm{Ga})$, arsenic (As) and indium (In) has a long tradition of usage as detection element. The composition in for example GaInAs has shown to be suitable for detection in the IR range, as the band-gap correspond to the photon energy in this range. Materials with small band gaps are sensitive to thermal noise making it necessarily to cool the detector elements.

\subsection{Colors from a Materials Perspective}

From a materials perspective, color can be created in different ways besides scattering as exemplified in previous chapter. The main examples are structural coloration and absorbing pigments or dyes. The optical material properties plays an important role here.

Structural coloration arise when the color of a surface is due to multiple reflections and interference in thin layers as discussed briefly in Chapter 2.2. Small structures of the same dimension as the wavelength, cause the transmitted (or reflected) light to interfere constructively in the structure giving a strong reflection corresponding to a specific wavelength (or color), or destructively causing a extinguishing of wavelength. Such phenomena are rather common in nature and were first documented by Hooke (in 1665) [26] and by Newton (in 1730) [27] when studying peacock feathers (as exemplified in Fig.3.1).

Many bird feathers, butterfly wings and beetle exoskeletons are structurally colored [28]. The white color of the beetle C. insulanus, studied i PAPER IV - V is also structurally colored. The internal structure of the thin beetle scales is built 


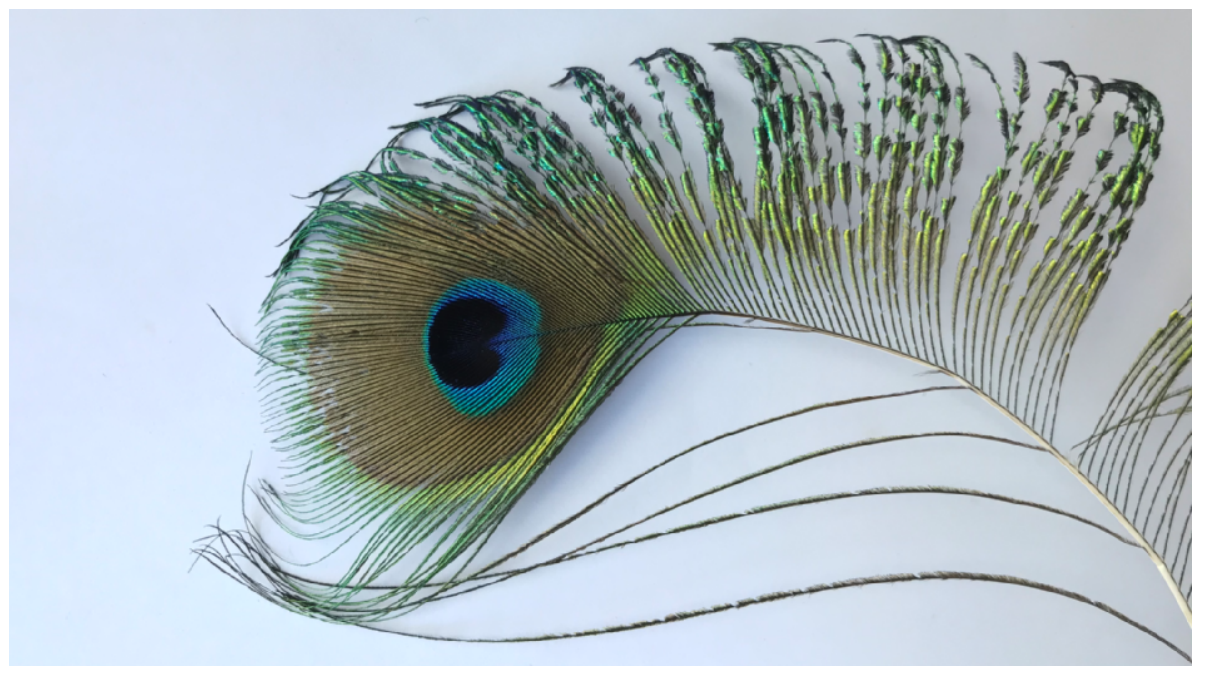

Figure 3.1. Peacock feathers is an example of early documented structural colors.

up by a random nano-fibril network. This network are of the same dimensions as wavelengths of visible light. The visible light is scattered whereby the beetle appears white. Several attempts have been made to mimic natural structural colors and produce bio-inspired artificial structures [29].

Besides structural colors, colors can be achieved through pigments. A pigment is a specialized molecule, that strongly absorbs light at a specific wavelength or in a wavelength range. The color of the object is then correlated to which wavelength of light that is not absorbed. The reflected or transmitted light is thus colored due to the wavelength-selective absorption.

For instance, chlorophyll is a molecule responsible for the green color of vegetation as it absorbs red and blue light. The molecules xanthophylls and carotene absorb UV and blue light. These molecules give the vegetation its yellow or red color in the autumn, and appear in vegetation once the chlorophyll has transformed to a colorless molecule.

A pigment is often an insoluble powder and has a high tinting strength. In the paint production process it can be added together with the binder, a substance that helps the resulting paint-suspension with adhesion. A dye on the other hand is soluble in the binder.

An example (also discussed below) is Rose Bengal which often is used in medicine, art, and electro-optical devices, for example. 


\subsection{Chromism and Examples of Adaptivity}

Adaptivity is a desired property in many circumstances, also in the field of camouflage. Adaptivity can be achieved using dynamic materials with inherent chromism. Chromism is the generic term for a phenomena when a material changes color due to external stimuli. There are many ways to classify their switching properties. One approach is by making a distinction in terms of organic or inorganic materials, and another is to consider the stimuli needed for a switching effect. Examples are thermo-, piezo-, electrochromic or chemically switching materials. For a chemically switchable material, the trigger of a color change may be a solvent, ions or a pH change.

a)

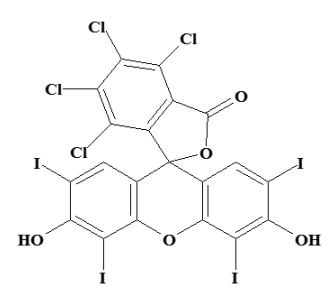

b)

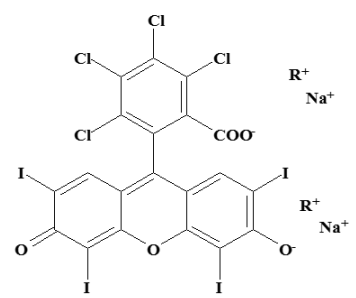

c)

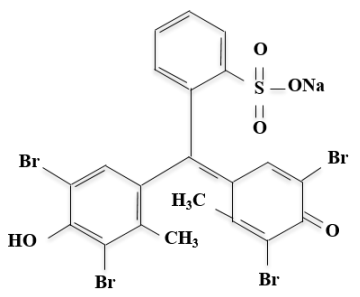

Figure 3.2. Chemical structure of two forms of Rose Bengal a) lactone form and b) salt, and c) the compound Bromocresol Green.

An example of an adaptive material is Rose Bengal (RB) (4,5,6,7-tetrachloro$2^{\prime}, 4^{\prime}, 5^{\prime}, 7^{\prime}$-tetraiodofluorescein). RB is commonly used as a dye in medicine practice, for diagnostics and treatments in biology research. It exist in several derivatives and also as salts. For example, sodium salt of Rose Bengal, with empiric formula $\mathrm{C}_{20} \mathrm{H}_{4} \mathrm{Cl}_{4} \mathrm{I}_{4} \mathrm{O}_{5} * 2 \mathrm{Na}$ and chemical structure as illustrated in Fig.3.2.b. It is a widely used dye, for example in a kind of eye drops to identify damage to the eye. Due to its staining properties it is possible to see a contrast between for example living or dead cells. The RB derivate switches between a dark pink and colorless (pale pink) state. The color switch of RB is explained through redox-induced changes in the electronic structure backbone (PAPER VI), and the material has been tested for applications such as bi-stable organic memories and in photovoltaic devices [30, 31].

Bromocresol Green (BG) (3,3',5,5'-Tetrabromo-m-cresolsulfon-phthalein) has the empirical formula $\mathrm{C}_{21} \mathrm{H}_{14} \mathrm{Br}_{4} \mathrm{O}_{5} \mathrm{~S}$. Its chemical structure is found in Fig.3.2.c. Bromo-cresol green is commonly used as $\mathrm{pH}$ indicator as it turns yellow for $\mathrm{pH}<3.8$ and blue for $\mathrm{pH}>5.4$. BG often plays a role in applications like growth media for microorganisms and titrations or is used in clinical practice as a diagnostic tool. A widespread application of BG is measurement of serum albumin concentration in blood to determine renal failure or liver disease [32]. BG is also used as chromogenic agent in camouflage swimmers [33]. BG can adopt the colors green and yellow, which are of relevance for camouflage. 


\subsection{Color Coordinates}

In order to quantify and describe colors, different coordinate systems are used for different purposes. In art or paint industry there is a need to discuss how colors harmonize and match together. Other color description systems focus on how different sensors perceive colors. Colors can also be mathematically described using different color coordinate systems.

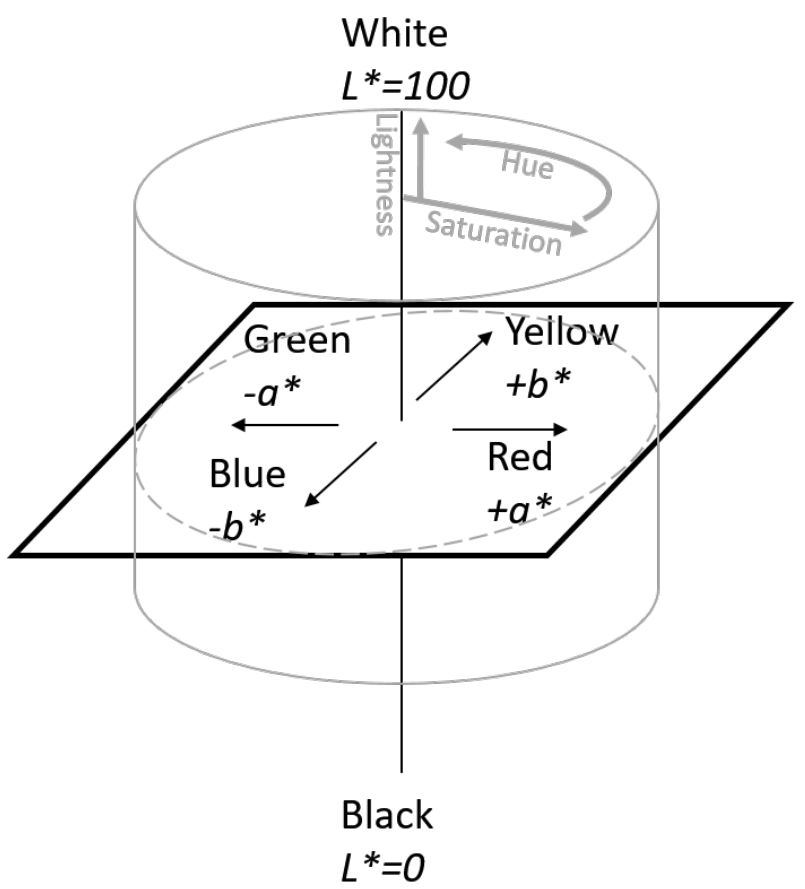

Figure 3.3. The CIELAB color space is presented in a cubic form. The scale is an approximately uniform color scale to visualize differences between colors. The $L$-scale range between 0 and 100 while the $a^{*}$ - and $b^{*}$-axes do not have a specific numerical limit. The HSL notation is presented in grey for comparance.

The 3D-color space coordinates system CIE $L^{*} a^{*} b^{*}$ defined by the International Commission on Illumination [34] is a common standard often used in science. This system is constructed with an attempt to have a subjective measure of the human eye and perception of brightness at daytime illumination conditions. Here lightness is specified through the label $L^{*}$, varying along a light-dark axis between 0 and 100 for diffuse surfaces, as illustrated in Fig.3.3. For specular surfaces the value can be $>100$. The red-green components are specified using $a^{*}$, where red color is denoted with positive numbers. To differentiate between yellow and blue, $b^{*}$ is used, accrediting positive numbers for yellowness. The CIE $L^{*} a^{*} b^{*}$ color co- 
ordinates can be related to a perceived color using a standard for comparing color values [34].

Different systems and standards are used to describe colors and their properties, viewed from different perspectives. The RGB system is based on the colors red, green and blue and the addition of the colors in different combinations to create other tints and shades. This system is based on the theory of the color perception of human eyes and is often used for representation of colors and images in electronic systems. In an additive color match every color is contributing with light. Mixing all colors gives white light.

In printing technology the CMYK-color set is used. The colors cyan, magenta and yellow (black) are colors combined to attained any other color. In printing technology subtractive color mixing is used, where a combination of the colors cyan, magenta and yellow yields black. Figure 3.4 illustrates the additive and subtractive synthesis of colors using the RGB and CMYK color systems.

\section{Color synthesis}

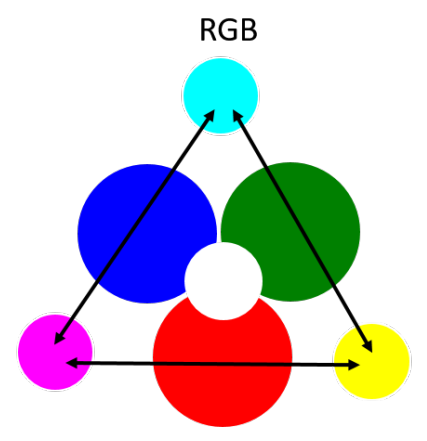

Additive

Red Green Blue $\bigcirc$ White

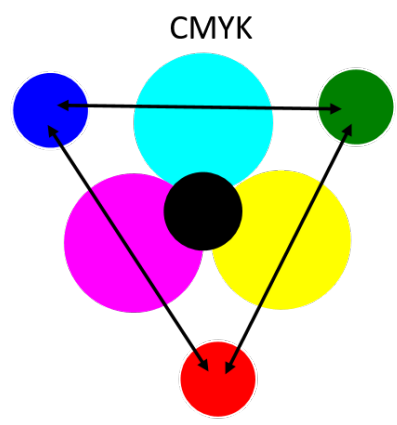

Subtractive

Cyan Yellow Magenta Black

Figure 3.4. Additive or subtractive color mixing processes uses different primary colors to attain the corresponding secondary colors.

An alternative representation of colors is the cylindrical HSL (or HSV) system, using hue, saturation and lightness (or value). The hue parameter is the angular dimension between the colors red, green and blue. The saturation dimension scales from pale tints to bright color. The lightness dimension scales between black and white. To compare images in a background with illumination from a computer screen the HSL system is convenient and was used in PAPER II when discussing contrast and detectability. 
Whiteness is a measure of how white a surface is. Many different definitions of whiteness are available and are used for different purposes. A common expression for calculating whiteness $W,[35]$ can be written,

$$
W=Y-1700\left(y-y_{n}\right)-800\left(x-x_{n}\right)
$$

Here $x$ and $y$ are chromaticity coordinates of the sample and determined from a ratio of the tristimulus values ${ }^{7} X, Y$ and $Z$ of the sample. $Y$ represents the relative luminance. $x_{n}$ and $y_{n}$ are then the chromaticity coordinates of a perfect diffuser. The higher value of $W$ the whiter is the surface, where 100 corresponds to a perfect diffuser. The whiteness of a beetle cuticle was calculated in PAPER IV.

\footnotetext{
${ }^{7}$ The tristimulus values are any three primary colors in an additive color model based on three colors.
} 


\title{
CHAPTER 4
}

\section{Optical Polarization}

\author{
"You can't find someone who doesn't \\ want to be found."
}

-Isabel Allende

This chapter contains a brief description of the theory of polarization of light, a property that we as humans are not able to see directly but that can be detected by sensors. However, when using polarizing sunglasses usually part of the light and disturbing reflections of the sun are removed, when filtering out one polarization direction.

\subsection{Polarization of Light}

Polarization is a wave property, determinded by the orientation of the electric field in relation to direction of propagation (here the $\hat{\mathbf{z}}$-direction is choosen) of the light beam. The light is totally polarized if the electric field components in the $x$ - and $y$-directions, $E_{x}(z, t)$ and $E_{y}(z, t)$, are totally correlated. Some examples are given below. For instance, if $E_{y}(z, t)=0$, the light is linearly polarized in the $x$-direction, as illustrated in Fig.4.1.a.

When the phase and amplitude are identical for the $x$ - and $y$-components, the light is linearly polarized $+45^{\circ}$ in relation to the $x$-axis. A $\pm 180^{\circ}$ phase difference between the $x$ - and $y$-components (half a wavelength) results in linearly polarized light. This is illustrated in Fig.4.1.b.

A phase difference of $\pm 90^{\circ}$ (a quarter of a wavelength) and identical amplitude in both $x$ - and $y$-directions corresponds to circularly polarized light. The states 
a)
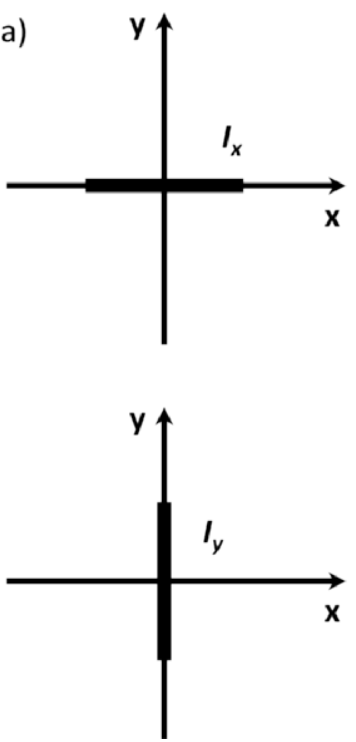
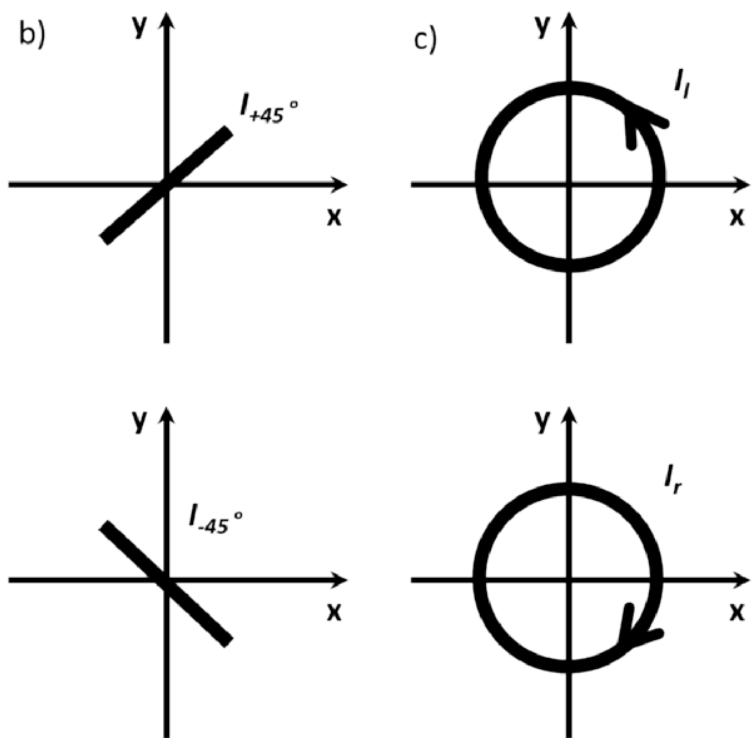

Figure 4.1. A schematic description of different polarization states. Illustrations of (a) linearly polarized light in the $\mathrm{x}$ - and $\mathrm{y}$-directions, (b) linearly polarized light in the $\pm 45^{\circ}$ directions and (c) left and right handed circularly polarized light.

discussed above are illustrated in Fig.4.1.c. With a phase difference of $\pm 90^{\circ}$ and different $x$ - and $y$-amplitudes, the light will be elliptically polarized. This will also be the case for any phase difference from $0^{\circ}, \pm 90^{\circ}$ or $\pm 180^{\circ}$ given that the $x$ - and $y$-components both are non-zero.

The polarization ellipse presented in Fig.4.2. is useful in the description of polarization state characteristics, which for example is discussed in PAPER IV. The fundamental properties of polarization can be expressed through its characteristics following here [15]:

The azimuth angle $\alpha$, defined for $-90^{\circ} \leq \alpha<90^{\circ}$, describes the polarization direction and the orientation of the major axis $a$ of the polarization ellipse in its plane. The ellipticity $e$, defined as the ratio between the minor and major axis, $b$ and $a$, of the polarization ellipse. $e=b / a$, is a measure of to which extent the reflected light is circularly or linearly polarized. The ellipticity has values in the range $-1 \leq e \leq 1$, where 0 corresponds to linearly polarized light and \pm 1 to circularly polarized light with right- or / left-handed polarization, respectively.

Just as the world-wide interpretation of left or right or clockwise and sun-wise are of directional importance, the conventions of use are significant. Left or right differ depending on how your nose points. Sun-wise counts differently depending on if you are north or south of the equator. Also polarization conventions vary and regarding handedness, different conventions are seen in optics and microwave 


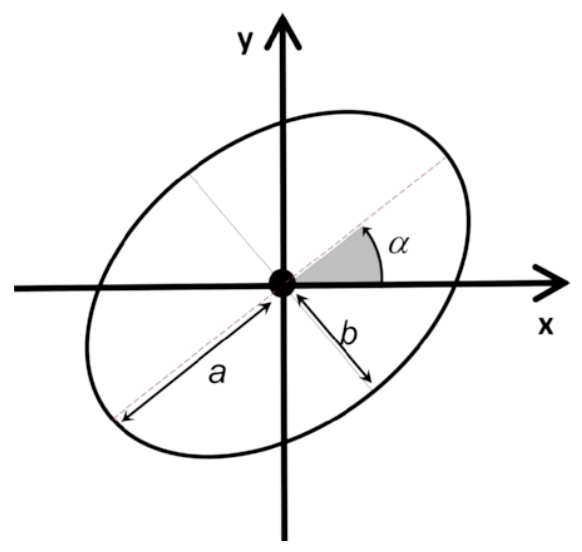

Figure 4.2. A schematic description of the polarization ellipse.

interpretations. This can be very confusing as the signs are the opposite. In this thesis a light wave propagating towards you with clockwise rotation of the electric field is defined as a right-handed polarization. A wave with an electric field rotating counter clockwise on its way towards you, is defined as having lefthanded polarization.

\subsection{Stokes-Mueller formalism}

To describe the polarization of light, the Stokes description is very useful [36]. The Stokes elements $I, Q, U, V$ are, for instance, convenient when describing a mixture of polarized and unpolarized light [15] and can be written as different combinations of the irradiances $I$ as in Eqs.4.1-4.4 below. In the equations the notation $<>$ refers to the time averaged value. $E_{x}(t), E_{y}(t), \delta_{y}(t)-\delta_{x}(t)$ and are defined in Eq.2.2.

$$
\begin{aligned}
& I=I_{x}+I_{y}=\frac{n}{2} \sqrt{\frac{\epsilon_{0}}{\mu_{0}}}\left(<E_{x}^{2}(t)>+<E_{y}^{2}(t)>\right) \\
& Q=I_{x}-I_{y}=\frac{n}{2} \sqrt{\frac{\epsilon_{0}}{\mu_{0}}}\left(<E_{x}^{2}(t)>-<E_{y}^{2}(t)>\right) \\
& U=I_{+45^{\circ}}-I_{-45^{\circ}}=n \sqrt{\frac{\epsilon_{0}}{\mu_{0}}}\left(<E_{x}(t) E_{y}(t) \cos \left(\delta_{y}(t)-\delta_{x}(t)\right)>\right)
\end{aligned}
$$




$$
V=I_{r}-I_{l}=n \sqrt{\frac{\epsilon_{0}}{\mu_{0}}}\left(<E_{x}(t) E_{y}(t) \sin \left(\delta_{y}(t)-\delta_{x}(t)\right)>\right)
$$

The Stokes element $I$ is often used for normalization, for instance, resulting in $I_{i}=1$ for the Stokes vector $\mathbf{S}_{i}=\left[I_{i}, Q_{i}, U_{i}, V_{i}\right]^{T}$, of the incoming light. The elements $Q$ and $U$ are representing the irradiances for linearly polarized light in the directions $x$ or $y$, and \pm 45 degrees respectively. Circular polarization is represented by $V$ in the right (or left-handed) preference. The convention within optics is a positive valued $V$ for right-handed circular polarization. The incoming, and outgoing Stokes vectors $\mathbf{S}_{i}$ and $\mathbf{S}_{o}$ are related through the Mueller-matrix $\overline{\mathbf{M}}$ [37] and its $16 m_{i j}$ elements,

$$
\mathbf{S}_{o}=\left[\begin{array}{c}
I_{o} \\
Q_{o} \\
U_{o} \\
V_{o}
\end{array}\right]=\left[\begin{array}{cccc}
1 & m_{12} & m_{13} & m_{14} \\
m_{21} & m_{22} & m_{23} & m_{24} \\
m_{31} & m_{32} & m_{33} & m_{34} \\
m_{41} & m_{42} & m_{43} & m_{44}
\end{array}\right]\left[\begin{array}{c}
I_{i} \\
Q_{i} \\
U_{i} \\
V_{i}
\end{array}\right]=\overline{\mathbf{M}} \mathbf{S}_{\mathbf{i}}
$$

Through a Mueller-matrix an interaction between light and matter can be described. Here we let an optical system be represented by the matrix. The different combinations of reflection or transmission coefficients are then expressed through the elements $m_{i j}$. In Eq.4.5 and below the matrix is normalized making $m_{11}=1$. The degree of polarization $P$ describes to what extent the light is polarized. $P$ is calculated as the ratio between the irradiance of the polarized part of the wave $I_{p o l}$ and the irradiance $I_{t o t}$. In general this can be expressed with the Stokes elements according to,

$$
P=I_{\text {pol }} / I_{\text {tot }}=\sqrt{\frac{Q^{2}+U^{2}+V^{2}}{I^{2}}}
$$

For a specific polarization state of the incoming light the Mueller-matrix elements $m_{i j}$, can be used to express $P$. For instance, the degree of polarization for $u n-p$ and $s$-polarized incoming light can be determined from,

$$
\begin{gathered}
P_{u}=\left[m_{21}^{2}+m_{31}^{2}+m_{41}^{2}\right]^{1 / 2} \\
P_{p}=\frac{\left[\left(m_{21}+m_{22}\right)^{2}+\left(m_{31}+m_{32}\right)^{2}+\left(m_{41}+m_{42}\right)^{2}\right]^{1 / 2}}{1+m_{12}} \\
P_{s}=\frac{\left[\left(m_{21}-m_{22}\right)^{2}+\left(m_{31}-m_{32}\right)^{2}+\left(m_{41}-m_{42}\right)^{2}\right]^{1 / 2}}{1-m_{12}}
\end{gathered}
$$




\subsection{Polarization and Camouflage}

Polarization sensing abilities are developed using different techniques both in the VIS and IR ranges. An early example is the development of a polarizing polymer, patented in 1933 [38], and further developed by Edwin H. Land to the polaroid instant camera. It had all the darkroom operations included in the film [39], which was revolutionary in its time. Due to the technological development it is nowadays almost outcompeted by digital technology. Hardware still used in the field of photography and camera technology include also different types of lenses and filters. These are being developed and functionalized as well.

Filters are often used to attain different polarization features from a regular VIS or IR camera. Examples of four classical imaging principles to filter out the polarimetric information are Division of time (using rotating filters), Division of amplitude (using multiple cameras), Division of aperture (using subapertures or multiple lenses), and Division of Focal Plane Array, FPA (by directly allowing integration of micropolarizers onto the different pixels) [5]. The different techniques all have their own advantages and disadvantages. For example, when filtering in time the speed is reduced. On the other hand spatial resolution is lost when using FPA.

The dominant impact on the polarization signature caused by the weather factor is the cloud cover. Molecules and aerosols in the atmosphere often cause the polarization state of light to change due to for example absorption and scattering as it propagates. Various matter interactions on the way from source to receiver, also affect the polarization state. Examples are reflection or emission by material surfaces. The relative orientation between the plane of incidence of the interfering surface and light path or emission is critical. The surface properties are an important part, as a rough surface depolarizes light more than a smooth surface does. Polarization state changes can also be caused by physical mechanisms such as birefringence (refraction) and dichroism ${ }^{8}$. The blue sky above is polarized, a phenomena widely used for orientation by for example insects.

\footnotetext{
${ }^{8}$ Birefringence is an optical property of a material for which the refractive index is varying with propagation direction. A dichroic filter selectively transmits a few wavelengths while reflecting other.
} 


\section{CHAPTER 5}

"The best and most beautiful things in the world cannot be seen or even touched - they must be felt with the heart".

— Helen Keller

This chapter is an introduction to camouflage materials in nature (our source of inspiration), and the materials studied - environmental reference materials as well as white and dyed biopolymer surfaces.

\subsection{Camouflage Materials in Nature}

An outstanding source of inspiration for camouflage is found in nature. Animals are adapted to their environment in a wonderful and rich way. There is a great number of examples that could be given [41]. One is the chameleon's mythical skin with inspiring camouflage transformation ability. It is mimicked using photonic crystal arrays embedded in thin films of a hydrogel with responsive properties. By expanding or contracting the photonic crystals, the color changes [40]. The polar bear has fur constructed in such a way that the hair and fur are insulating from both water and coldness, not unlike bird feathers. This has, for instance, inspired to camouflage textiles [42]. On the contrary, the silver ants that are able to survive in the hot desert thanks to their quickness and their structural metal like silver finished triangular hairs covering the back. These hairs reflect the heat through a combination of Mie scattering and internal reflection [43] and can inspire to improved thermal solutions and camouflage. 
The cephalopods, the marine 'queens of camouflage' have an incredible ability to transform and change color to adopt to the background. Cephalopods, like squids, can vary colors rapidly with the purpose of camouflage or signalling [44]. Reversible proteins switching between two phosphorylation configurations of its reflectin proteins make this possible. These proteins are the driving source of tune-ability. Their ability cover both change of color and of brightness [45]. A great volume of work has been performed to identify the tunability source $[46,47]$ and try to imitate this [48]. Still a few challenges remain to understand and solve [49].

To turn to nature to find solutions of engineering problems, i.e. through the use of biomimetics ${ }^{9}$ never seems to be outdated. The main building blocks of living materia are built up with only a few elements, mainly carbon $(\mathrm{C})$, hydrogen $(\mathrm{H})$, oxygen $(\mathrm{O})$, and nitrogen $(\mathrm{N})$. Here, complex structures such as the common biopolymers cellulose in vegetation, chitin in shell of crustaceans, molluscs, and insects cuticles together with proteins are included. In recent years the ability of fabrication of nanostructures has increased and biological structures can be mimicked more effectively. Studies of polarizing natural nanostructures such as beetle cuticle [51] increase the understanding of the structure's significance for the optical response.

A futuristic camouflage might be to produce or cultivate materials through breeding and use of selected patterns or color using DNA. An early example was presented at the Living Light conference 2016 in San Diego where the possibility to prioritize selected patterns and colors when breeding snakes and butterflies was discussed $[52,53]$.

\subsection{Materials in this Study}

The materials involved in this study are of two categories. The first category includes environmental background reference materials, as illustrated in Fig.5.1. Some examples are car paint, bricks and aluminium ( $\mathrm{Al}$ ) of different roughness, leaves and glass. The second category of studied materials is samples based on biopolymers, such as a natural beetle, and cellulose and protein based surfaces. Dyes with potential to be used for coloring of the biopolymers were described in Chapter 3.

\subsubsection{Background Reference Materials}

To better understand the response from a polarization sensor, studies on reference materials are valuable. The reference materials studied were chosen from an urban environmental context containing car paint, building materials and park vegetation etc. The reference surfaces were chosen to encompass different materials and

\footnotetext{
${ }^{9}$ Biomimetics defined as meaning imitating nature for engineering solutions, was introduced by Schmitt in the midst of the 20th century [50].
} 
variations in roughness and emissivity. The investigated samples (PAPER III) can be summarized in the following list.

- A selection of different kinds of paints: A generic red car paint to compare with the specific Volvo red paint. Further a green reference paint [54] also used in PAPER II and a grey paint.

- Aluminium and brick materials of two different roughnesses.

- Park vegetation in the form of fresh leafs from a Swedish columnar poplar.

- Transparent microscope glass.

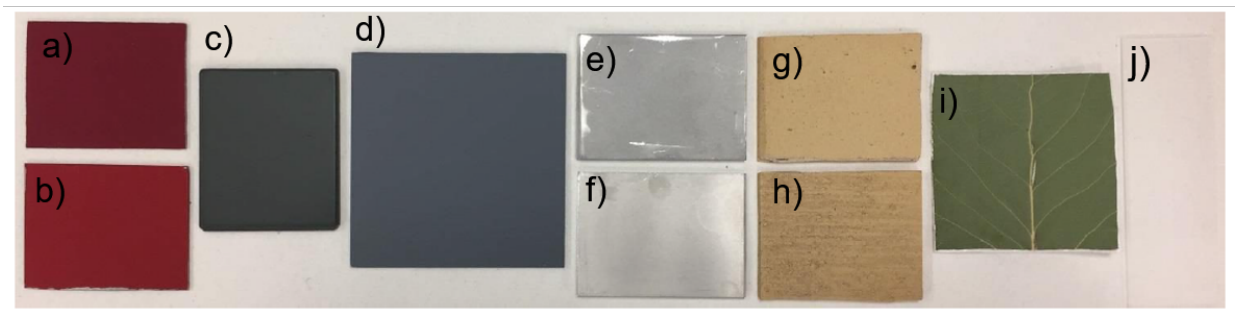

Figure 5.1. The sample selection include various samples that could be found in an environmental background: (a) red auto paint, (b) generic red Volvo paint, (c) CUBIgreen, (d) grey paint, (e) blasted $\mathrm{Al}(6 \mathrm{~kg} / \mathrm{cm} 2)$, (f) blasted $\mathrm{Al}(3 \mathrm{~kg} / \mathrm{cm} 2)$, (g) yellow brick (smooth), (h) yellow brick (rough), (i) leaf from a Swedish columnar poplar, (j) transparent microscope glass. Reprinted from Paper III with permission. (C)2020 SPIE.

\subsubsection{Biopolymers}

To the second category of studied materials belongs cellulose, chitin as well as proteins. These can be viewed in Fig.5.2.

\section{Cellulose and Cellulose Nano-Fibril Foams}

Cellulose is the most abundant organic biopolymer on earth and the base of, for example, wood and vegetation in nature. Recent research and development have shown [55] that cellulose can be used in a wide range of applications besides traditional use in building materials, fuel and furniture, for example. A great potential is predicted as cellulose can be transformed and turned into for example cellulose nanofibrils and those can in turn be formed to thin films, foams or even $3 \mathrm{D}$ printed creations. In this thesis cellulose foams were studied.

Foams can be used in applications ranging from thermal insulation, as flotation devices and packing materials [56], to prohibit fire [57], for water purification [58], and selective removal of oil [59]. Today non-degradable synthetic foams are often used. For environmental and sustainability reasons degradable materials such as 
cellulose foams could be used when and where appropriate. However, many problems, some related to stability, are yet to be solved.

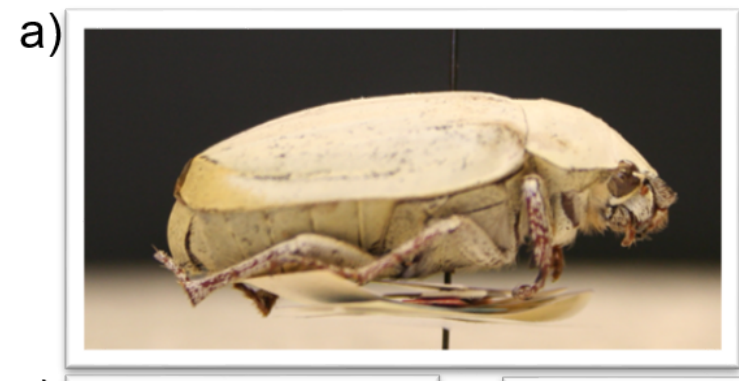

c)

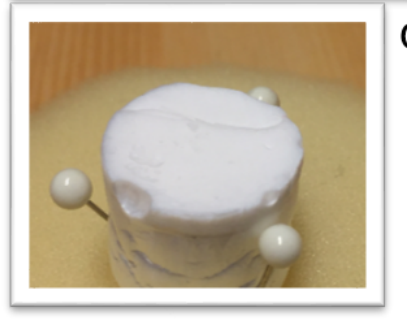

d)

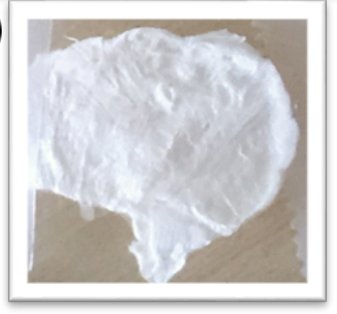

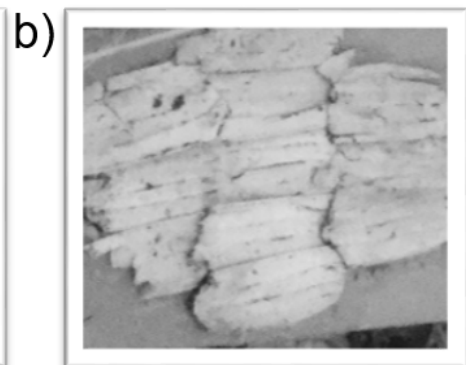

e)

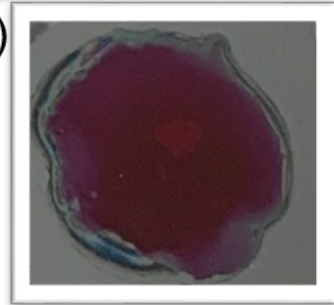

Figure 5.2. White natural biopolymer materials and a dye studied in this thesis. (a) Cuticle of the beetle Cyphochilus insulanus, (b) Cyphochilus insulanus cuticle assembled on a substrate (CIC), (c) a cellulose nano-fibril (CNF) foam, (d) protein nano-fibril (PNF) as foam, and (e) the dye Rose Bengal.

An example of a studied cellulose foam can be seen i Fig.5.2.c. The foams were produced from cellulose nanofibrils $(\mathrm{CNF})$ through a freeze-drying process resulting in lightweight bulks [60], a white soft puck with aligned cell walls. These CNF foams are very white and diffusely scattering and have been optically characterized in this work (PAPER VI). The foams were kindly provided by Stockholm University and prepared according to description in Ref. [60].

\section{Chitin and Beetle cuticles}

The second most abundant biopolymer in nature is chitin. Chitin is a long-chain polymer of N-acetyl- glucosamine, $\left(\mathrm{C}_{8} \mathrm{H}_{13} \mathrm{O}_{5} \mathrm{~N}\right)_{n}$. It is the primary component in the cell walls of fungi and the exoskeletons of arthropods such as insects and thereby also beetles. The structure of chitin is in some sense comparable to cellulose, forming crystalline nanofibrils. Chitin is often found in combination with a protein (sclerotin) or calcium carbonate to form strong composites as in beetle cuticle and crustaceans, respectively. In its function, there is a resemblance between chitin and the protein keratin, where the latter belongs to a family of fibrous structural proteins. It is a key material for building up hair, nails, feathers, claws, skin and spider webs. The protein keratin is efficient in protecting the epithelial cells from stress and damage. 
The extensively studied white beetle Cyphochilus insulanus (Moser ${ }^{10} 1918$ ) originates from south east of Asia, and has been found to scatter visible white light brightly due to the internal structure [10,61, 62, 63]. Development of white surfaces in different areas have found its inspiration from such structures. It has for example been proposed to develop paper with thinner coatings with maintained whiteness [64] or whiter fabric [65]. Several attempts to mimic the structure have been made as the interest in similar materials and structures is growing. Manipulation of polymers [66], [67], [68], [69], utilization of cellulose and inversed nanofibril cellulose glass [70] are a few examples.

In this study measurements were performed on the beetle as is and on cuticle removed from the beetle and assembled on a substrate, as can be seen in Fig.5.2.a and b. Results are presented in PAPER IV and V.

\section{Protein and Hen Egg White Lysozyme}

Proteins ${ }^{11}$ are organic macro-molecules, built up by more than 50 amino acids units in long chains and exist in several compositions. Proteins are, together with polysaccharides, fat and nucleic acids, the basis for all life. An old name for proteins was egg whites.

In this study hen egg white lysozyme (HEWL) was used. Lysozyme ${ }^{12}$, is an enzyme, common in egg white, tears, saliva and milk. It is used in pharmaceuticals for cancer treatment and treatment of bacterial infections. The reason for this is its ability to destroy the cell wall of bacteria, i.e., it is an antimicrobial agent. Lysozyme (1,4,ß-N-acetylmuramidase) comprise 129 amino acids. The protein sample(s) as seen in Fig.5.2.d(-e)., was prepared in a grain mix self-assembling process as described in PAPER V. The films were lifted from a liquid surface and freeze dried to attain a free-standing film.

\footnotetext{
${ }^{10}$ Moser was the auctor, i.e. the one classifying and giving the beetle its name.

${ }^{11}$ The word protein was first used by the Swedish scientist Jöns Jacob Berzelius (who like me, but earlier, attended 'Katedralskolan' in Linköping) in a letter to the Dutch collegue Gerardus Johannes Mulder in the early 19-th century.

${ }^{12}$ Lysozyme was discovered by Alexander Fleming in the early 1920's [71]. In 1928 he discovered penicillin.
} 


\section{CHAPTER 6}

Methods

"If you find a path with no obstacles, it likely leads nowhere."

- Catherine DeVrye

This chapter contains a brief description of experimental and modeling techniques used in this work. The main experimental methods were reflection spectrometry, scatterometry and ellipsometry.

\subsection{Experimental Techniques}

The main methods used in the study were the three experimental techniques spectrometry, scatterometry and Mueller-matrix spectrometric ellipsometry. Measurement results from these more or less directly correspond to the first three camouflage criteria (reflection, gloss and degree of polarization) described in PAPER I and Chapter 1. Scanning electron microscope (SEM) was used as a complement. Reflection spectrometry, is a method in which the reflection properties of materials as well as wavelength dependencies can be measured. A spectrometer is an instrument that can be used to measure spectral resolved optical properties. Separate instruments are used in the UV-VIS-NIR and the TIR wavelength regions. In the shorter wavelength band, it is common with instruments measuring wavelengths one by one by diffraction gratings. In the infrared region a Fourier transform (FT) technique is often implemented. For an FTIR instrument, based on a scanning interferometer, the investigated surface is illuminated with all wavelengths simultaneously. The reflectance wavelength dependency is achieved through a mathematical Fourier transformation done by the instrument software. In the application of concern not only the specular reflectance, but also the diffuse 
reflectance or scattering properties are of interest. These are possible to measure using reflection spectrometers combined with an integrating sphere ${ }^{13}$, as illustrated in Fig.6.1.

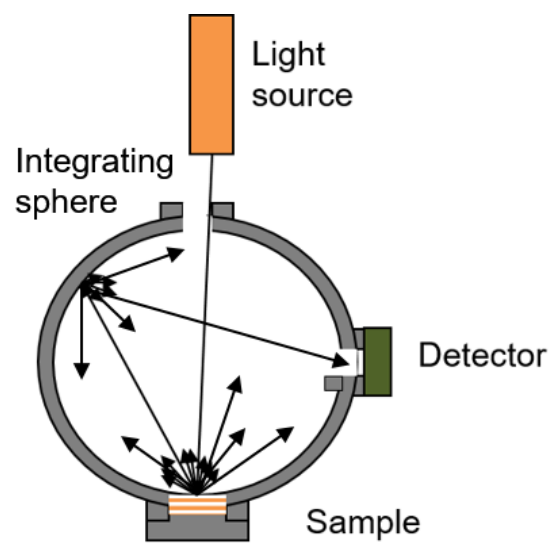

Figure 6.1. Configuration of the measurement method Spectral Directional Hemispherical Reflectance (SDHR).

The spectral directional hemispherical reflectance (SDHR) ${ }^{14}$ can be measured once an integrating sphere is installed. Light from a certain angle illuminates the sample and is then scattered onto the walls of the integrating sphere. After multiple scattering the light is collected by a detector. In this work the SDHR data is labelled $R_{S D H}$. To minimize the impact of polarization effects from the incoming beam, measurements often are performed close to normal incidence (in our cases at $8^{\circ}$ and $9^{\circ}$ respectively). The integrating sphere allows measurements of the total reflectance $\left(R_{t o t}\right.$, specular and diffuse) and diffuse reflectance $\left(R_{D}\right)$, separately. The degree of diffuse reflectance (DoDR) is defined using the parameter,

$$
\gamma_{D}=R_{D} / R_{t o t}
$$

that is, the ratio between the diffuse and total reflectance. $\gamma_{D}$ is a useful parameter when discussing diffuseness and diffuse surfaces.

The reflected light is often measured without any polarization preference. However, polarization filters can be used to control the polarization of the incident beam. In this work, filters were used for measurements with $s$-or $p$-polarization in the variable incident angle reflectance measurements of PAPER III. For calibration,

\footnotetext{
${ }^{13}$ An integrating sphere is a hollow sphere internally covered with a diffusely reflecting coating. The only openings are for entrance and exit of the light.

${ }^{14}$ With spectral directional hemispherical reflectance is meant the total spectral data integrated over a full hemisphere in the chosen wavelength range.
} 
reflectance standards with specular or diffuse properties matching the substrates are used. Either a Spectralon ${ }^{15}(\mathrm{~B})$ diffuse reflectance standard with a reflectance of $99 \%$ (UV-NIR) or a diffusely reflecting gold surface, Infragold@), with a reflectance of $95 \%$ (TIR). Besides the wavelength dependent reflection properties from a surface, material specific properties such as absorption resonances can be revealed from the retrieved reflectance spectrum.

Scatterometry is a method used to measure scattered light. The angle dependent scattering properties can be studied by measuring the bi-directional reflectance distribution function (BRDF), a function $f_{B R D}$ of five variables, wavelength included. The bi-directionality of the function depend on both the incident direction $\left(\theta_{i}, \phi_{i}\right)$ and the scattering direction $\left(\theta_{r}, \phi_{r}\right)$, illustrated in Fig.6.2.

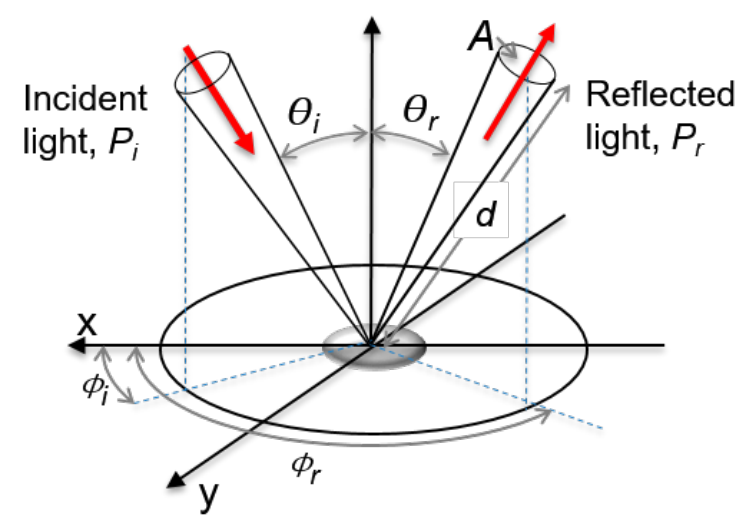

Figure 6.2. Configuration of the measurement method Scatterometry (BRDF measurements).

By measuring the reflectance for selected incident angles in a half hemisphere, it is possible to determine how the incident $s$ - or $p$-polarized light is reflected in space. The available wavelengths of our BRDF instrument were initially $633 \mathrm{~nm}$ and 3.39 $\mu \mathrm{m}$ and was later expanded with $853 \mathrm{~nm}$ and $1550 \mathrm{~nm}$. The approximate beam diameters were $3-5 \mathrm{~mm}$. The BRDF in units of inverse steradians was first defined by Nicodemus [72]. The BRDF is approximatively described by Stover [73] as the ratio between the differential radiance $P_{r}$ and irradiance $P_{i}$ and follows,

$$
f_{B R D} \approx \frac{P_{r} / \Omega_{r}}{P_{i} \cos \theta_{r}},[1 / s r]
$$

$P_{i}$ is then the incident radiant flux on the surface and $P_{r}$ is the scattered power reaching the detector. The solid angle $\Omega_{r}$ is determined by the distance $r$ between sample and detector, and the illuminated detector aperture area $(A)$, according

\footnotetext{
${ }^{15}$ Spectralon is a fluoropolymer and is a highly diffusely reflecting material.
} 
to $\left(\Omega_{r}=A / r^{2}\right)$. However, to adjust the size of the illuminated area to its corresponding size when viewed from the scatter direction, the correction factor $\cos \theta_{r}$ is needed. Also, polarization and wavelength dependence are suppressed in the equation for easier interpretation. The value of $f_{B R D}$ can be described as the directional reflectance per unit solid angle of the collected scattered light.

For a Lambertian surface, described in Chapter 2, i.e. an ideally diffuse scatterer, the measured $f_{B R D}$ would be a constant and the same for all scattered angles $\theta_{r}$ in Fig.6.2. For a Lambertian surface, the $f_{B R D}$ can also be calculated from the spectral directional hemispherical reflection $R_{S D H}$ at a specific wavelength. With the notation $f_{L B R D}$ we can write

$$
f_{L B R D}=\frac{R_{S D H}(\lambda)}{\pi}
$$

With near-Lambertian in this thesis is meant that a $f_{B R D}$ diffuse single-valued baseline can be defined in a way so that it can be compared with the calculated value. That is $f_{B R D} \approx f_{L B R D}$.

Ellipsometry is an optical analysis method often used to investigate the composition and determine the optical properties of thin films. It is based on the difference in polarization state between the incident and reflected light beam. The analysis of the change in polarization of a beam upon reflection is a central part of the technique. A dual compensator ellipsometer often follows the set-up as shown in Fig.6.3, where the light emerging from a light source goes through a polarizer and a compensator before reflection on the sample. After reflection, the beam once again takes the path through a compensator and then an analyzer (a polarizer) before it is collected by a detector.

From the measurements the complex ellipsometric parameter $\rho$, which is the ratio between the (complex-valued) Fresnel reflection coefficients $r_{p}$ and $r_{s}$, are received. $\rho$ can be expressed in polar form by using the ellipsometric angles $\Psi$ and $\Delta[15]$,

$$
\rho=r_{p} / r_{s}=\tan \Psi e^{i \Delta}
$$

After analysis, the dielectric function and other optical and structural properties of the sample can be derived from $\rho$. In the simple case with an (non-ideal) ambientbulk system it is sufficient to use the pseudo-dielectric function $\langle\epsilon\rangle$ which can be derived through inversion of Eq.6.4 in combinations with Eqs. 2.3-2.4.

$$
<\epsilon>=\sin ^{2} \theta\left[1+\frac{(1-\rho)^{2}}{(1+\rho)^{2}} \tan ^{2} \theta\right]
$$

$\langle\epsilon>$ will be equal to $\epsilon$ for an ideal flat surface. For multi-layered samples, containing interfaces and surface roughnesses, a more profound analysis is needed to obtain useful information about the optical and structural properties. 


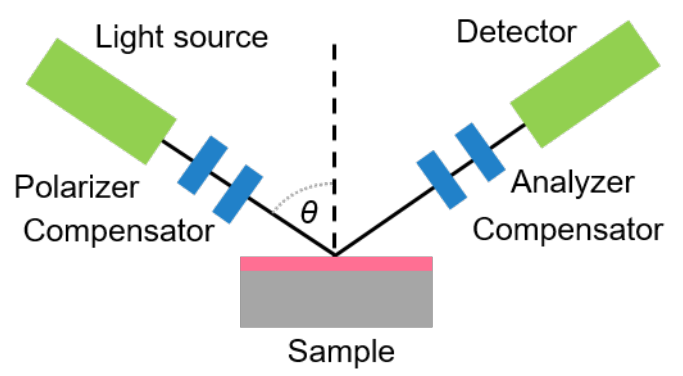

Figure 6.3. Configuration of a Mueller-matrix spectroscopic ellipsometer.

There are different kinds of ellipsometers. Standard ellipsometry may be used when there is no coupling between the orthogonal polarization components. A more powerful method is the Mueller-matrix spectroscopic ellipsometry (MMSE) which also allows to determine depolarization, for instance via data degree of polarization $P$, described in Eq.4.6-4.9. A realization of this technique proposed by Azzam and Bashara [15] is accomplished through a dual rotation-compensator ellipsometer, allowing multiple incident polarization states (linear, circular and elliptical). In a MMSE setup, the illuminating light is using multiple polarization states in the measurements, i.e. several different incident Stokes vectors $\mathbf{S}_{i}$. In the analysis of the reflected Stokes vector, $\mathbf{S}_{o}$, all 16 Mueller-matrix elements in the 4x4-matrix $\overline{\mathbf{M}}$ (described in Chapter 4.2) can be determined through the relation $\mathbf{S}_{o}=\overline{\mathbf{M}} \mathbf{S}_{i}$. Often the received data is used to model sample properties to obtain film thicknesses or sample compositions.

Microscopy is a technique used to study objects or surfaces at a very fine scale. With the higher resolution and magnification of an advanced microscope, structures not visible to the naked eye are revealed. Scanning electron microscope (SEM) images are obtained by scanning focused beams of electrons over a surface. The atoms of the sample and the electrons of the beam interact. Different signals with information about the surface are then collected, such as topography, composition or cross-section. The combination of beam position and detected signal intensity is used to yield the image. The microscope is used under high vacuum. A Leo 1550 instrument with a Gemini field emission column ${ }^{16}$ was used in our studies. For higher contrast, samples were cooled in liquid nitrogen. Non-conducting samples needed a pre-treatment in terms of deposition of a thin metal layer using sputtering. In this work platinum was used on the beetle $C$. insulanus. In Fig.6.4 the small scales covering the cuticle of the beetle $C$. insulanus and the tiny 'shark-tooth' structures on the scales, as well as the scales internal structure can be seen.

\footnotetext{
${ }^{16}$ SEM field emission column, especially designed for low accelerating voltages.
} 
a)

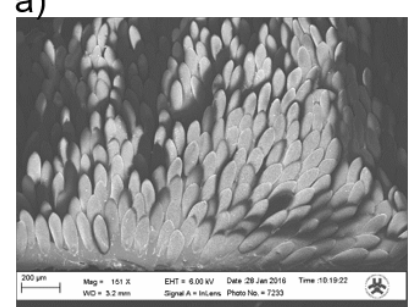

d)

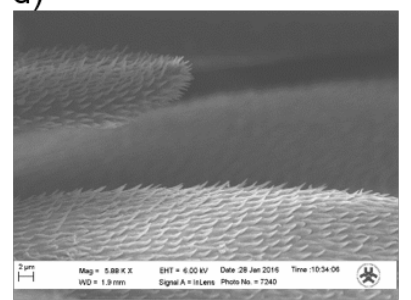

g)

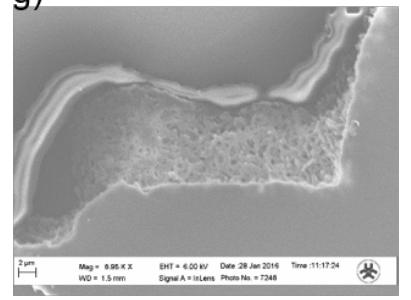

b)

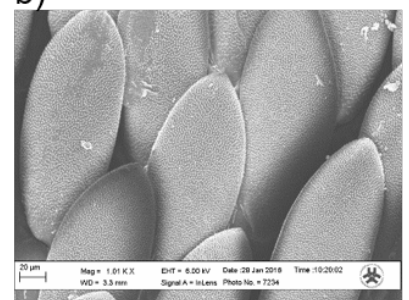

e)

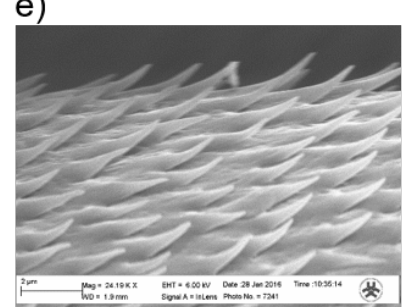

h)

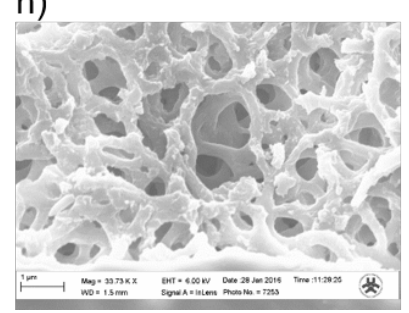

c)

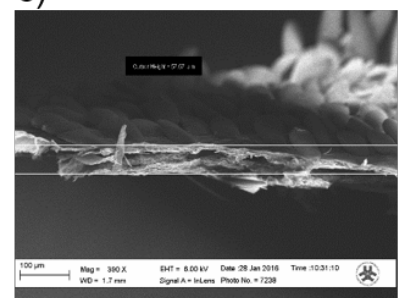

f)

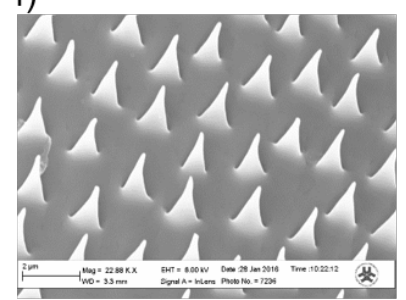

i)

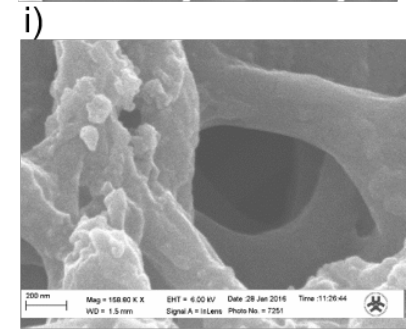

Figure 6.4. The fine characteristics of $C$. insulanus can be visible through SEM using different magnifications. (a-c) The thin scale(s) covering the cuticle in different views. (d-f) In a close-up view a fine shark-tooth structure on the outside of the thin scales become visible. ( $\mathrm{g}-\mathrm{h})$ Through a broken scale a nice view of the internal unordered fibril structure of the scales is visible.

\subsection{Calculations and Modeling}

Not all relevant information can be directly measured. Sometimes relationship between the different measurements must be calculated or modeled to obtain relevant results. Different modeling techniques are used for different purposes to extract results from experimental findings. A few examples are briefly explained below.

\subsubsection{Optical Modeling}

When an electromagnetic field $E(\omega)$ interacts with an atom or molecule, the system can resonate by vibrating or rotating generating absorption bands in the VIS or IR range. A brief descriptive analogy can be made using the approach made by Hendrik Lorentz using a spring model as illustrated in Fig.6.5.a. Two masses $\left(m_{1}\right.$ and $\left.m_{2}\right)$ are connected through a spring describing an elastic force. The masses can represent an electron and a heavy nucleus or represent two atoms in 
a molecule. In the case of low mass as for electrons the oscillation will be high mainly resulting in resonances in the visible while heavier atomic masses will give resonances predominately in the infrared.
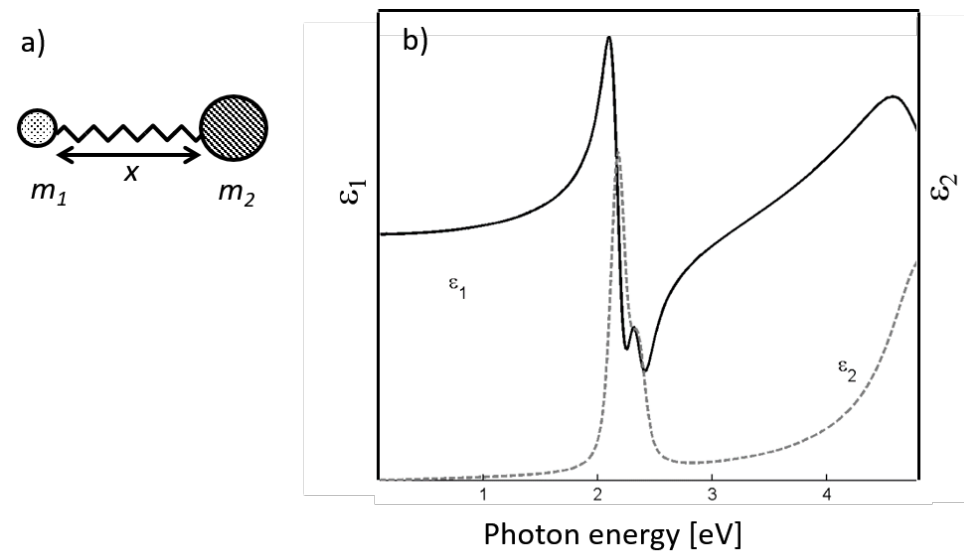

Figure 6.5. Illustration of (a) the mass-spring system in the classic spring-model used to describe the Lorentzian resonances of the Lorentz expression. (b) the relation between $\epsilon_{1}$ and $\epsilon_{2}$ of a combination of two Lorentzian resonances. From the dynamic Rose Bengal studies (PAPER VI), [74] used with kind permission.(C)2011 Elsevier B.V.

When a material is irradiated with a harmonic electromagnetic field $E(\omega)$ the absorption resonance peaks will occur at some frequency $\omega=\omega_{0}$. The dielectric function $\epsilon$ according to the Lorentz model can then be derived [14]

$$
\epsilon(\omega)=\epsilon_{\infty}-\frac{\omega_{\rho}^{2}}{\left(\omega^{2}-\omega_{0}^{2}+i \omega / \tau\right)}
$$

here $\epsilon_{\infty}$ is the relative permittivity for a infinite frequency. The resonance broadening is related to the lifetime $\tau$ and the plasma frequency $\omega_{p}$, the resonance frequency of all contributing electrons. If $\omega_{0}=0$ we have a simple free electron model, the Drude model ${ }^{17}$.

An example of a resonance in the visible is shown in Fig.6.5.b., where the dielectric function is plotted as a function of photon energy in electron volt $(\mathrm{eV})$. A Lorentz oscillator [16], or the model above, can be used when describing material specific absorption resonances, peak(s) that can be observed for dielectric and semiconductor materials.

Here $\epsilon_{2}$ (the imaginary part of the dielectric function) is illustrated as a function of photon energy of the interacting electromagnetic field. The photon energy is inversely proportional to the wavelength. $\epsilon_{2}$ is further related to absorption

\footnotetext{
${ }^{17}$ Paul K.L. Drude integrated optics with Maxwell's teories of electromagnetism [75]. He is also contributed to the theory behind ellipsometry.
} 
properties (described in Chapter 2.5) and is dependent on $\epsilon_{1}$ through the KramerKronig relation ${ }^{18}[14]$. Unknown optical and structural parameters of a complex layered sample may be determined through the use of a combination of different model features, such as the Lorentz oscillators, and reference data. In the modeling process the parameters of the model are iteratively matched to the experimental data. To measure a 'goodness of fit' [76] a mean square error (MSE) function can be used.

\subsubsection{Other Modeling Software}

The software CompleteEASE (J.A. Woollam Co., Inc.) was used for data analysis and preparation of the MMSE results (PAPERS IV-VI).

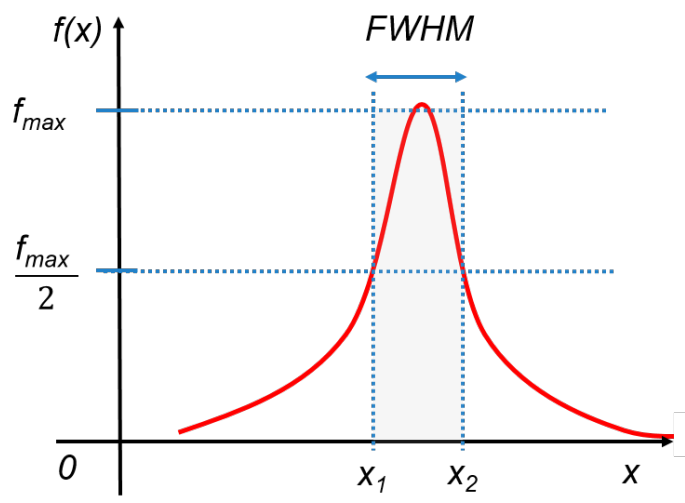

Figure 6.6. Illustration of the points of interest when determing the the Full Width Half Maximum value.

Lorentz resonances and other peaks are often analyzed using the Full Width Half Maximum (FWHM). That is, the width of the peak at the half maximum height, as illustrated in Fig.6.6. The FWHM value is also useful when defining the bandwidth in signal processing, to determine the spectral width of a source or to describe characteristics of absorption or specular peaks from BRDF-measurement. The latter was done in PAPER V.

The whiteness $W$, specified by Eq.3.1, was calculated for the beetle from spectral reflectance measurements using MATLAB to be able to compare with results published by others (PAPER IV).

The modeling software TAITherm@ [77] can be used to model thermal distribution and heat flows in different systems. The combination of a temperature

\footnotetext{
${ }^{18}$ The Kramer-Kronig relation describes how the real and imaginary parts of a complex analytic function in a stable physical system are connected. Due to causality and analytical conditions the real part can be calculated from the imaginary part, or the other way around.
} 
distribution model of a system at a specific temperature and a materials database, allows the emitted radiation from a surface to be calculated (PAPER II).

Terrtex(R) is a software originally developed at FOI. It is now further developed at the company BAE Systems@. It was intended to be used to extract conspicuous features in images and thereby provide a measure of detectability of objects placed in the same background. The software does not deliver an absolute measure of detectability, however. For objects in the same background it can be used to calculate a relative measure, here called GSNR (Generalized Signal to Noise Ratio) [78] (PAPER II). The GSNR may be converted to a measure called detection probability (DP), which in turn is related to detection range and camouflage effectiveness. 


\section{Summary of Included Papers and My Contribution}

"Success is getting what you want.

Happiness is wanting what you get."

— Ingrid Bergman

This chapter summarizes the papers included in the thesis, my contribution, and shortly present the findings of this research. The papers can be split into the two categories Evaluation Criteria of Camouflage (PAPER I - III) and Studies of Bio-Inspired Materials and Dyes (PAPER IV - VI). Related papers not included in the thesis are listed at the end of the chapter.

\subsection{List of Papers and My Contributions}

\subsubsection{Evaluation Criteria for Camouflage}

\section{PAPER I}

A Review of Materials for Spectral Design Coatings in Signature Management Applications, Kent E. Andersson and Christina Åkerlind;

Proc. of SPIE, 9253 92530Y, 1 - 20 (2014).

My contribution: discussions about content and part of the writing.

\section{PAPER II}

Evaluation Criteria For Spectral Design Of Camouflage, Christina Åkerlind, Jan Fagerström, Tomas Hallberg, and Hans Kariis;

Proc. of SPIE, 9653 965303, 1 - 13 (2015). 
My contribution: taking initiative to the study, performing part of the simulations and writing a major part of the manuscript.

\section{PAPER III}

Optical Polarization - Background and Camouflage, Christina Åkerlind, Tomas Hallberg, Johan Eriksson, Hans Kariis, and David Bergström;

Proc. of SPIE, 10432 1043204, 1 - 14 (2017).

My contribution: taking initiative to the study and writing parts of the manuscript.

\subsubsection{Studies of Bio-Inspired Materials}

PAPER IV, Scattering and Polarization Properties of the Scarab Beetle Cyphochilus insulanus Cuticle, Christina Åkerlind, Hans Arwin, Tomas Hallberg, Jan Landin, Johan Gustafsson, Hans Kariis, and Kenneth Järrendahl; Appl. Opt., 54/19, 6037 - 6045 (2015).

My contribution: taking active part in planning, performing a large part of measurement and the analysis, discussing the results and writing a major part of the manuscript.

\section{PAPER V}

Optical Studies of White Surfaces for Camouflage Applications, Christina Åkerlind, Tomas Hallberg, Lei Wang, Niclas Solin, and Kenneth Järrendahl;

In Manuscript.

My contribution: taking active part in planning, performing most of the measurements and analysis and writing a major part of the manuscript.

\section{PAPER VI}

Optical Properties and Switching of a Rose Bengal Derivative: A Spectroscopic Ellipsometry Study, Christina Åkerlind, Hans Arwin, Fredrik L. E. Jakobsson, Hans Kariis, and Kenneth Järrendahl;

Thin Solid Films, 519, 3582 - 3586 (2011).

My contribution: taking active part in planning, performing measurement and analysis and writing a major part of the manuscript.

\subsection{Results}

\section{PAPER I}

This paper contains a review of a selection of relevant camouflage applications and available materials. A vast range of materials can be useful for spectral design coatings in signature management applications. The reviewed materials have 
been classified roughly in order of complexity from single layers of paint, to three dimensional (3D) structures, and into biomimetic structures and metamaterials. These are all promising candidates for camouflage, but have also other areas of application. In Paper I, also the six camouflage criteria are introduced. The idea is that further studies on these can aid demonstration of military utility by spectral design using the so called 'ladder model'.

\section{The major results are:}

- A description of development trends of materials for signature management.

- An attempt to connect the military utility with physical material properties through the so-called 'ladder model'.

- Introduction and description of the concept of six camouflage evaluation criteria for future use in spectral design and camouflage development.

\section{PAPER II}

In this paper the three evaluation criteria reflectance, gloss and emissivity are in focus together with the visual and thermal contrast. The contrast between a generalized object and the background is studied in images of different kinds. The hue, saturation and lightness levels in the visible images were differentiated, which was helpful in the evaluation of detectability. In IR the thermal information fills the same function. The dilemma of camouflage validation becomes clear, as good results are not visible, only failures.

\section{The major results are:}

- Discussion on how the six camouflage criteria correlate.

- The whiteness level was here more important for the detection range of our model target than the hue and saturation.

- For high emissivity surfaces, the temperature was important, whereas for low emissivity surfaces the mirrored background was more important regarding detectability.

- Further studies are needed to focus on the impact of roughness and texture of surfaces in order to achieve low contrast to the background.

- Also polarization and dynamic effects need to be further studied.

- The 'ladder model' must be further elaborated to be useful in the way intended. The interface between the different steps must be investigated to achieve comparability between the dimensioning parameters of the different ladder rungs.

\section{PAPER III}

The intention of this paper was to give an introduction to polarization properties of the background (through a brief literature study) and state of the art insight 
in camouflage and sensor related research. The review findings were accompanied with polarization separated reflectance measurement of a few urban background and target relevant materials, for example car paint, brick and leaf samples. The degree of linear polarization and the degree of diffuse reflection upon incident $p$ or $s$-polarized light was measured. The relationship between degree of diffuse reflection and degree of linear polarization as well as the Umov-effect [79] was discussed. The results may be useful in future modeling of polarimetric properties.

\section{The major results are:}

- Degree of linear polarization and degree of diffuse reflection with incident $p$ - or $s$-polarized light were determined for a few reference background and target materials.

- A specularly reflecting surface gives rise to a higher degree of linear polarization. A diffusely reflecting surface often gives rise to a lower degree of linear polarization.

- A surface with high reflectance causes a lower degree of linear polarization than a similar surface with a lower reflectance, due to the Umov effect.

- Some samples show a larger degree of linear polarization at longer rather than shorter wavelengths. This is due to wavelength dependent scattering effects.

\section{PAPER IV}

This paper focuses on biological materials for a future biomimetic approach of camouflage development. The white beetle Cyphochilus insulanus is optically characterized using the three available techniques of relevance for the camouflage criteria revealing the reflection, scattering and polarization properties of the beetle as a whole. The white light reflecting beetle scales was diffusely scattering with close to Lambertian properties in the visible range.

\section{The major results are:}

- Reflection and scattering properties as well as degree of polarization for the cuticle of the scarab beetle $C$. insulanus.

- For the beetle as whole a whiteness value of 42 was received, lower than the value of 60-65 attained from a single scale in other studies [10].

- The IR reflection properties of the beetle were significantly lower than in the visible range.

\section{PAPER V}

In this paper three white bio-polymeric samples, the white beetle $C$. insulanus, cellulose nanofibril foam and protein nanofibril surfaces are studied. Their optical characteristics are compared and related to the camouflage criteria introduced in Paper I. The reflectance, scattering and polarization properties are measured and discussed comparing with properties of snow. 


\section{The major results are:}

- Reflection, scattering and polarization properties of three diffusely scattering bio-polymeric samples.

- All three samples have high reflectance in VIS.

- When comparing the reflectance in the visible for the white beetle, it was lower than for reported values of snow, while the reflectance of cellulose foam and protein foam had a better match. The reflectance of our samples was generally higher in NIR and IR compared with those reported of snow.

- Near-Lambertian scattering is clearly obtained in VIS at small angles for all three samples. The samples appear more specular at $1550 \mathrm{~nm}$ but still the beetle and cellulose foam are classed as near-Lambertian.

- The degree of polarization is generally low for the protein foam, but a greater angular and spectral variation are found for the beetle and cellulose foam sample.

- The diffusely scattering, non-flat surfaces were difficult both to align and measure.

- Results may be used as input in polarimetric scattering modeling.

\section{PAPER VI}

In this paper thin films of the chemically switching dye Rose Bengal are studied. Reversible switching properties are shown. Their thicknesses were determined using multi-sample-analysis. The film thickness is of importance to understand the switching mechanism.

The major results are:

- Optical properties and film thicknesses of different chemical states of RB.

- Data for further for device composition.

\subsection{Papers not Included in this Thesis}

a) Transparent nanocellulose metamaterial enables controlled optical diffusion and radiative cooling

Sampath Gamage, Evan Kang, Christina Åkerlind, Samim Sardar, Jesper Edberg, Hans Kariis, Thomas Ederth, Magnus Berggren, and Magnus P. Jonsson;

Submitted May 2020 to Journal of Materials Chemistry C.

b) Balancing the radar and long wavelength infrared signature properties in concept analysis of combat aircraft - A proof of concept, Carina Marcus, Kent Andersson, and Christina Åkerlind;

Aerospace Science and Technology, 71, 733-741 (2017). 
c) On the polarization of light reflected from beetle cuticle, Hans Arwin, Lia Fernández del Río, Christina Åkerlind, Sergiy Valyukh, Arturo MendozaGalván, Roger Magnusson, Jan Landin, and Kenneth Järrendahl;

Materials Today: Proceedings 4A, 4933-4941 (2017).

d) Exploring optics of beetle cuticles with Mueller-matrix ellipsometry, Hans Arwin, Roger Magnusson, Lía Fernández del Río, Christina Åkerlind, Eloy Muñoz-Pined, Jan Landin, Arturo Mendoza-Galván, and Kenneth Järrendahl;

Materials Today: Proceedings, 1S, 155-160 (2014).

e) Spectroscopic ellipsometry and vector network analysis for determination of the electromagnetic response in two wavelength regions, Christina Åkerlind, Anna Jänis, Hans Kariis, Hans Arwin, and Kenneth Järrendahl;

Physica Status Solidi (c), 5, 1089-1092 (2008).

g) Polymer based devices with adaptable infrared reflection and transmission, Christina Nilsson ${ }^{19}$, Eva Hedborg Karlsson,and Hans Kariis;

Proc. of SPIE, 6192 61921U-1 (2006).

h) Thiophene-Cored 2,2-Bis(methylol)propionic Acid Dendrimers for Optical-Power-Limiting Applications, Robert Vestberg, Christina Nilsson ${ }^{19}$ Cesar Lopes, Per Lind, Bertil Eliasson, and Eva Malmström;

Journal of Polymer Science, Part A: Polymer Chemistry, 43, 1177-1187 (2005).

i) Development of low-emissive camouflage paint: Final report, Tomas Hallberg, Tiina Niinimäki-Heikkilä, Eva Hedborg Karlsson, Paasi Salonen, Christina Nilsson, ${ }^{19}$ and Anna Jänis;

FOI (2005).

${ }^{19}$ Nilsson was the author's maiden name prior to 2007. 


\title{
CHAPTER 8
}

\section{Conclusions and Outlook}

\author{
"One never notices \\ what has been done; one can only see \\ what remains to be done."
}

- Marie Curie

This chapter contains conclusions, a retrospective part and outlook of future research. The latter is based on what would be a natural continuation of this limited piece of work if resources are available.

\subsection{Conclusion}

Reference surfaces from primarily an urban background environment have been studied together with white and dyed biopolymers from a camouflage application perspective. Optically related parameters of relevance for the camouflage criteria have been studied. An attempt is made to climb the rungs in the 'ladder model', which relate the parameters relevant on a fundamental materials level to the final dimensioning request of military utility through different system level steps. Additionally, a special focus has been put on reflection, scattering and polarization properties to meet the future sensor threat. A contribution to increased knowledge and basis for future research on modified whiteness for camouflage applications is made. More research is needed in the field of low observables and low observability, also regarding generalized whiteness for diffuse controlled emissivity in TIR. 


\subsection{Retrospective}

In the half-time work, the so-called Licentiate thesis, I suggested three legs, a stable base, for the future work: biomimetic materials, polarization properties and metamaterials. What happened with my intention for the future?

I have had the fortune to look at natural materials and found out that there is so much more to learn that not even a life-time of studies would be sufficient. However, when adding together the findings of many researchers, each person is contributing with his or her part. The pace, with which the pieces of the puzzle is put together will increase.

Since the first published study on the brilliant white beetle $C$. insulanus [10], a creature that happened to come to stay in (my) focus, a lot has happened in the related scientific fields. Publications can be found in a diversity of fields: structure optimization, optical characterization of properties, inspiration and attempts of replica and look-alikes, modeling and simulation of diffusive surfaces, thin films and bulk materials etc. Also closely related subjects such as biology and evolution theory may be important in future applied research when eventually breeding a selected pattern.

Regarding polarization properties of materials and backgrounds, the work has only started. Until now, a small number of materials have been investigated and reported from a camouflage point of view. Nature is exhibiting interesting and vivid variations revealed in literature reviews and researches documentation. Even if the search was for 'dull' and 'not prominent' materials, unexpected explanations of the important difference between black and white from a horses and horse flies' perspective brightens up the task and opens up for new understandings.

Metamaterials are originally engineered material with properties not naturally occurring in nature. Usually its internal components are arranged in a way so that the structure is of dimensions smaller than the macroscopic dimensions for which they have impact. A combination of precise size, geometry, shape and orientation within the material, is what enables manipulation of electromagnetic waves. By absorbing, enhancing, blocking or bending the waves, new and extraordinary abilities can be achieved that is not possible to accomplish with use of conventional materials. Examples are materials with negative index of refraction, super lenses allowing imaging below the diffraction limit, or gradient-index materials to accomplish earthquake shielding structures or invisibility cloaks. From a signature management view, invisibility is the utopia. It has been shown that 'invisibility' is already possible, at least for a few angles and wavelengths [80]. In art, literature, film and music 'invisibility' is almost becoming a legend. But the myth does not only belong in the histories but is part of a future reality with the invisible man reappearing. In any case, metamaterials did not come to be a part of this thesis. 


\subsection{Outlook}

There is a lot to learn and study regarding nature, natural materials and bioinspired materials. Often the answer to one question generates at least ten new. A few examples: What are the optical properties of other white natural structures such as for example birch bark, garlic peel, egg shell etc.? What other (than optical) properties must be considered for a bio-inspired material to be suitable in camouflage applications? How can the cellulose or protein fibers be treated to be more useful? Are there other biopolymeric or bio-inspired fibers or foams more appropriate for camouflage use than those studied here? Which fabrication technique is suitable?

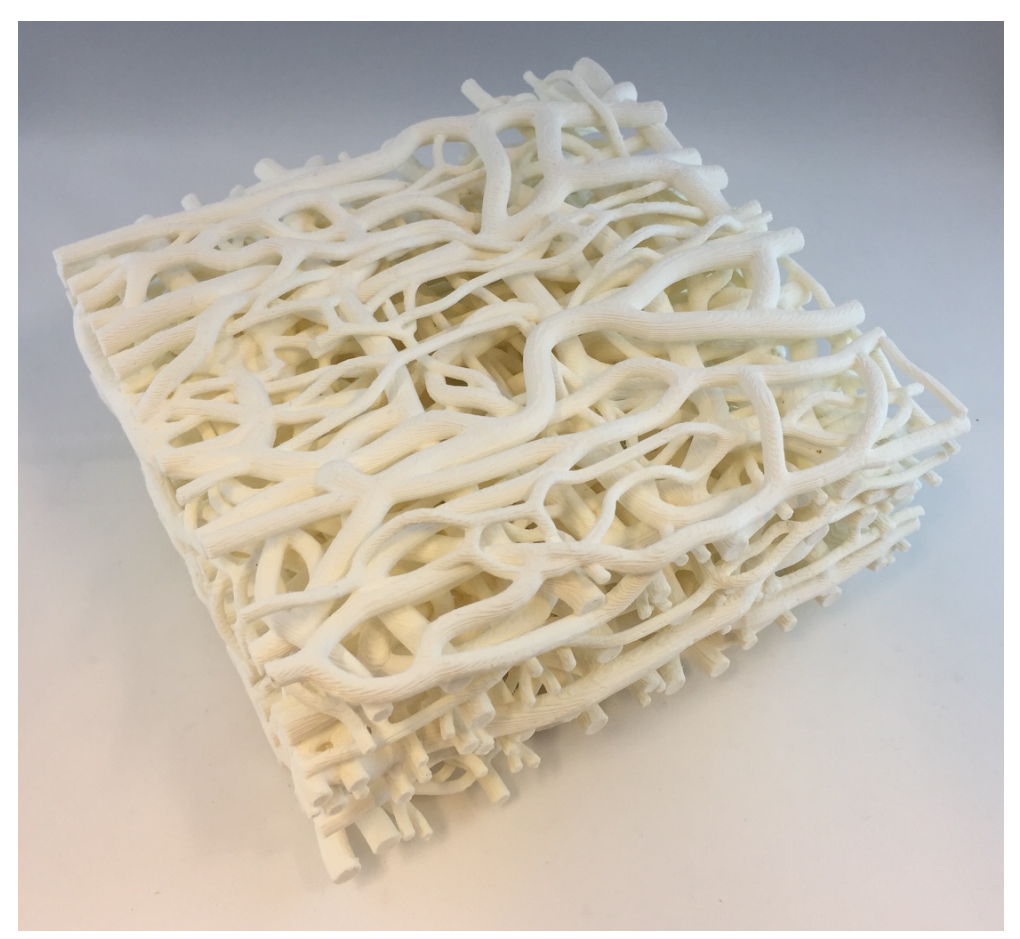

Figure 8.1. Pilot 3D-print of a simplification of the internal structure of the beetle $C$. insulanus cuticle. Thanks to Pär Glendor for preparing the CAD and Pontus Köhler for 3D-printing.

3D-printing is a fairly new trend in material fabrication. What about a scaled up 3D-printed beetle structure? A pilot 3D-print of a scaled up beetle structure, made from a CAD model of a non-periodic block, can be viewed in Fig.8.1. The $3 \mathrm{D}$-printed beetle structure was a rescale from dimensions at nanoscale to micrometer $\operatorname{size}^{20}$, without paying notice to the refractive index change needed for

\footnotetext{
${ }^{20}$ This means a magnification of about 10000 times.
} 
a proper transformation. Time works for us, and 3D-printers with a resolution of proper dimensions are now available. The delicate problem of adjusting choice of material for suitable dimensions to accomplish 'broad-band whiteness' needs further investigation.

A more realistic and cost-conscious approach to attain unordered materials is probably through quilts or electrospun fibers of natural origin. Cellulose fibers could possibly be used to spin tissues and textiles. It is already possible to spin films with threads of different thicknesses [81]. Also quilts or textiles of polar bear hair imitations should be investigated further [42]. Alternative use of this kind of surfaces could be whiter textile, paper or humidity sensors etc.

a)

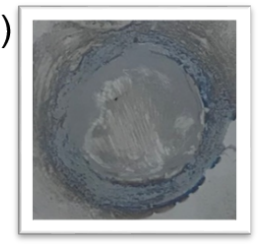

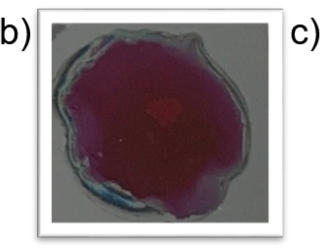

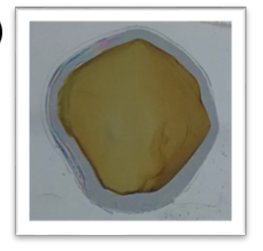

Figure 8.2. Protein nanofibrils on a silicon substrate. a) Undyed reference sample, Sample dyed with b) Rose Bengal and c) Bromocresol Green, respectively.

To investigate a broader range of coloring and also delve deeper into the dynamic aspects of camouflage, a study to dye biomimetic materials has been initiated. This should be seen as a proof of concept rather than a demonstration of the final and outmost solution. The material to be dyed was self-assembling proteins, or more specifically hen egg white lysozyme. The dyes used as example were Bromcresol Green (BG) and Rose Bengal (RB), both with documented chromic properties. Thin films of dyed protein deposited on silicon substrates were studied with the same characterization techniques as previously used. This produced thinner films compared with the previously investigated free-standing foams. The next step will be to derive the properties of the dyed thin protein films and compare the reflectance, gloss and degree of polarization with the foams.

The initial purpose of studying the white beetle, was to find out if 'white structures' could improve camouflage in TIR. 'White' in this context would mean broad band equal-level high reflectance in long wavelength IR. Absorption peaks from material different from the background material, will risk destroying the background match. We therefore must consider designing a material composition with an emitting window in a less sensor friendly frequency range. As a contrast, attention must be paid to the fact that nature is rather 'black' in the IR range, i.e. has a low reflection.

From a military utility perspective affordability and 'good enough' are important properties. How can these be determined? One way forward can be modeling 
the polarimetric scattering properties of an object using the collected material and surface data. It would deepen the understanding of how the use of a material could affect the signature of an object if it was applied on a large object or vehicle. The polarimetric-BRDF model is suitable for this $[82,83,84,85]$. A deeper understanding of abilities of the new sensors will also help in the further development of camouflage. The use of real polarization sensitive imaging sensors and cameras, to collect images of samples in different ways, will help to map sample properties and also better understand what characteristics is enhanced when viewing through a polarization sensor. Outdoor experiments and field trials are beneficial for further understanding and realism, however, the constantly changing parameters of the outdoor environment makes experiments much harder to control.

A future research direction depends on the possible and chosen perspectives and the gap, i.e. where research is requested and needed. Research will either be a knowledge gap filler, a solution finder or a combination. Time will tell. 
[1] Allen, W. L., Cuthill, I. C., Scott-Samuel, N. E. \& Baddeley, R. Why the leopard got its spots: relating pattern development to ecology in felids. Proc. R. Soc. B 278, 1373-1380 (2011).

[2] Chris Barton (Author), V. N. I. Dazzle Ships: World War I and the Art of Confusion (Kindle Edition, 2017).

[3] Hartcup, G. Camouflage A History of Concealment and Deception in War (Pen and Sword Military, 2008).

[4] Horvath, G., Pereszlanyi, A., Åkesson, S. \& Kriska, G. Striped bodypainting protects against horseflies. R. Soc. open sci. 6, 181235 (2019).

[5] Schott, J. R. Fundamentals of polarimetric remote sensing - Tutorial texts in optical engineering, vol. v. TT81 (SPIE, 2009).

[6] Arwin, H., Magnusson, R., Landin, J. \& Järrendahl, K. Chirality-induced polarization effects in the cuticle of scarab beetles, 100 years after michelson. Phil. Mag. 92, 1583-1599 (2012).

[7] Arwin, H. et al. On the polarization of light reflected from beetle cuticle. Materials Today: Proceedings 4/4, 4933-4941 (2017).

[8] Andersson, K. \& Akerlind, C. A review of materials for spectral design coatings in signature management applications. Proc. of SPIE 9253, 92530Y-124 (2014).

[9] Åkerlind, C. Optical Studies of Materials for Spectral Design (Linköping Studies in Science and Technology Thesis, No. 1712, 2015).

[10] Vukusic, P., Hallam, B. T. \& Noyes, J. Brilliant whiteness in ultrathin beetle scales. Science 315, 348 (2007). 
[11] Gracheva, E., Ingolia, N., Kelly, Y. \& et al. Molecular basis of infrared detection by snakes. Nature 464, 1006-1011 (2010).

[12] Maxwell, J. C. A dynamical theory of the electromagnetic field. Philosophical Transactions of the Royal Society of London 155, 459-512 (1865). This article accompanied a December 8, 1864 presentation by Maxwell to the Royal Society.

[13] Born, M. \& Wolf, E. Principles of Optics (Cambridge University Press, 2013), 9th edn.

[14] Arwin, H. Thin Film Optics and Polarized Light (Hans Arwin, 2014), the aureus edn.

[15] Azzam, R. \& Bashra, N. Ellipsometry and Polarized Light (Elsevier Science Publisher, 1977).

[16] Hecht, E. Optics (Addison-Wesley, 2002).

[17] Lambert, J. H. Photometrie; Photometria Sive De Mensura et Gradibus Luminis, Colorum et Umbrae (Verlag von Wilhlem Engelmann, Leibzig, 1760).

[18] Palmer, J. M. The measurement of transmission, absorption, emission, and reflection, in: Handbook of Optics, vol. II Devices, Measurements, and Propertie, second ed. (McGraw-Hill, Inc., 1995).

[19] Krane, K. Modern Physics (John Wiley \& Sons, 1983).

[20] Burns, D. A. \& Ciurczak, E. W. Handbook of Near-Infrared Analysis, vol. 13 of Practical Spectroscopy Series (Marcel Dekker, Inc., 1992).

[21] Schmieder, D. E. \& Walker, G. W. The Infrared Electro-Optical Systems Handbook, Countermeasure Systems, vol. 7 (Infrared Information and Analysis Center and SPIE, 1993).

[22] Taylor, F. Colour Technology for artists, craftsmen, and industrial designers (Oxford university Press, 1962).

[23] Wrigth, W. D. The Measurement of Colour (Adam Hilger LTD, 1969).

[24] Herschel, W. Experiments on the refrangibility of the invisible rays of the sun. Philos. Trans. Roy. Soc. London (1800).

[25] Rogalski, A. History of infrared detectors. Opto-Electron. Rev. 20 (2012).

[26] Hooke, R. Micrographia: or some Physiological descriptions of minute bodies made by magnifying glasses with observations and inquiries thereupon ( $\mathrm{J}$. Martyn and J. Allestry, 1665).

[27] Newton, I. Opticks (4th Ed. reprinted by Dover Publications, 1730).

[28] Kinoshita, S. Structural Colors in the Realm of Nature (World Scientific, 2008). 
[29] Dumanli, A. G. \& Savin, T. Recent advances in the biomimicry of structural colors. Chem. Soc. Rev. 45 (2016).

[30] Pradhan, B. \& Pal, A. J. Organic heterojunction photovoltaic cells: role of functional groups in electron acceptor materials. Solar Energy Materials and Solar Cells 81, 469 - 476 (2004).

[31] Jakobsson, F. et al. On the switching mechanism in rose bengal-based memory devices. Org. Electron 8, 559-565 (2007).

[32] Product Information, BCG (Bromocresol Green) Albumin Assay Kit (2014).

[33] Karshalev, E. et al. Multistimuli-responsive camouflage swimmers. Chemistry of Materials 30, 1593-1601 (2018).

[34] Cie technical report, colorimetry. Technical Report, International Commission on Illumination (Commission internationale de l'éclairage) (2004).

[35] Westland, S. CIE Whiteness, vol. Encyclopedia of Color Science and Technology (Springer, Berlin, Heidelberg, 2015).

[36] Stokes, G. G. On the composition and resolution of streams of polarized light from different sources. Transactions of the Cambridge Philosophical Society 9 (1852).

[37] Mueller, H. Memorandum on the polarization optics of the photoelastic shutter. Technical Report 2 of the OSSRD project OEMsr-576 (1943).

[38] Land, E. H. \& Friedman, J. S. Polarizing refracting bodies (1933).

[39] Land, E. H. Some aspects on the development of sheet polarizers. Journal of the Optical Society of America 41, 957-963 (1951).

[40] Dong, Y. et al. Chameleon-inspired strain-accommodating smart skin. ACS Nano 13, 9918-9926 (2019).

[41] Cott, H. B. Adaptive Coloration in Animals (Methuen, Oxford University Press, 1940).

[42] Cui, Y., Gong, H., Wang, Y., Li, D. \& Bai, H. A thermally insulating textile inspired by polar bear hair. Adv. Mater. 30, 1706807 (2018).

[43] Shi, N. N. et al. Keeping cool: Enhanced optical reflection and radiative heat dissipation in saharan silver ants. Science 349, 298-301 (2015).

[44] Hanlon, R. T., Messenger, J. B. \& Young, J. Z. Adaptive coloration in young cuttlefish (Sepia officinalis L.): the morphology and development of body patterns and their relation to behaviour. Phil. Trans. R. Soc. Lond. B320, B320437-487 (1988). 
[45] Levenson, R., Bracken, C., Bush, N. \& Morse, D. E. Cyclable condensation and hierarchical assembly of metastable reflectin proteins, the drivers of tunable biophotonics. The journal of biological chemistry 291, 4058-4068 (2016).

[46] Levenson, R. et al. Calibration between trigger and color: Neutralization of a genetically encoded coulombic switch and dynamic arrest precisely tune reflectin assembly. The journal of biological chemistry 294, 16804-16815 (2019).

[47] Byrne, J. H. (ed.) The Oxford Handbook of Invertebrate Neurobiology (Oxford University Press, 2019).

[48] Xu, C., Stiubianu, G. T. \& Gorodetsky, A. A. Adaptive infrared-reflecting systems inspired by cephalopods. Science 359, 1495-1500 (2018).

[49] Phan, L. et al. Dynamic materials inspired by cephalopods. Chem. Mater. 28, 6804-6816 (2016).

[50] Yu, K., Fan, T., Lou, S. \& Zhang, D. Biomimetic optical materials: Integration of nature's design for manipulation of light. Progress in Materials Science 58, 825-873 (2013).

[51] Järrendahl, K. \& Arwin, H. Polarizing Natural Nanostructures; In Ellipsometry of Functional Organic Surfaces and Films, vol. 52 (Springer Series in Surface Sciences book series, 2018).

[52] Milinkovitch, M. C. United Viging Colours: Integrating Skin Colour in the Framework of Evolutionary Developmental Biology (Living Light Conference Abstract book, 2016).

[53] Thayer, R. C. \& Patel, N. H. Genetic and evolutionary bases for thein film structural coloration in the Buckeye butterfly (Living Light Conference Abstract book, 2016).

[54] Malaplate, A., Grossmann, P. \& Schwenger, F. Cubi: a test body for thermal object model validation. Proc. SPIE 6543 (2007).

[55] http://wwsc.se. Wallenberg wood science center (2020).

[56] Gibson, L. J. \& Ashby, M. F. Cellular Solids Structure and Properties, 2nd ed. (Cambridge University Press, 1997).

[57] Ratzer, A. History and development of foam as a fire extinguishing medium. Ind. Eng. Chem. 48, 2013-2016 (1956).

[58] Standeker, S., Novak, Z. \& Knez, Z. Adsorption of toxic organic compounds from water with hydrophobic silica aerogels. J. Colloid Interface Sci. 10, 362-368 (2007). 
[59] Zhang, Z., S(́) be, G., Rentsch, D., Zimmermann, T. \& Tingaut, P. Ultralightweight and flexible silylated nanocellulose sponges for the selective removal of oil from water. Chem. Mater. 26, 2659-2668 (2014).

[60] Gordeyeva, K. Design, processing and properties of lightweight foams from cellulose nanofibers (2018).

[61] Åkerlind, C. et al. Scattering and polarization properties of the scarab beetle Cyphochilus insulanus cuticle. Applied Optics 54, 6037 (2015).

[62] Luke, S. M., Hallam, B. T. \& Vukusic, P. Structural optimization for broadband scattering in several ultra-thin white beetle scales. Applied Optics 49, 4246 (2010).

[63] Burresi, M. et al. Bright-white beetle scales optimise multiple scattering of light si. Scientific Reports 4, 6075 (2015).

[64] Hallam, B. T., Hiorns, A. G. \& Vukusic, P. Developing optical efficiency through optimized coating structure: biomimetic inspiration from white beetles. Applied Optics 48, 3243 (2009).

[65] Yip, J., Ng, S.-P. \& Wong, K.-H. Brilliant whiteness surfaces from electrospun nanofiber webs. Text. Res. J. 79, 771-779 (2009).

[66] Syurik, J. et al. Bio-inspired, large scale, highly-scattering films for nanoparticle-alternative white surfaces. Scientific Reports 7, 46637 (2017).

[67] Syurik, J., Jacucci, G., Onelli, O. D., Hol̈scher, H. \& Vignolini, S. Bio-inspired highly scattering networks via polymer phase separation. Adv. Funct. Mater. 28, 1706901 (2018).

[68] Zou, W. et al. Biomimetic polymer film with brilliant brightness using a onestep water vapor-induced phase separation method. Adv. Funct. Mater. 29, 1808885 (2019).

[69] Wang, M., Ye, X., Wan, X., Liu, Y. \& Xie, X. Brilliant white polystyrene microsphere film as a diffuse back reflector for solar cells. Materials Letters 148, 122-125 (2015).

[70] Caixeiro, S., Peruzzo, M., Onelli, O. D., Vignolini, S. \& Sapienza, R. Disordered cellulose-based nanostructures for enhanced light scattering. ACS Appl. Mater. Interfaces 9, 7885-7890 (2017).

[71] Fleming, A. \& Wright, A. E. On a remarkable bacteriolytic element found in tissues and secretions. Proc. R. Soc. Lond. B 93, 306-317 (1922).

[72] Nicodemus, F. E., Richmond, J. C., Hsia, J. J., Ginsburg, I. W. \& Limperis, T. Geometrical considerations and nomenclature for reflectance. National Bureau of Standards (NBS) monograph 160 (1977).

[73] Stover, J. Optical Scattering: Measurement and Analysis (McGraw-Hill, Inc., 1990). 
[74] Åkerlind, C., Arwin, H., Jakobsson, F. L. E., Kariis, H. \& Järrendahl, K. Optical properties and switching of a rose bengal derivative: A spectroscopic ellipsometry study. Thin Solid Films 519, 3582-3586 (2011).

[75] Drude, P. Lehrbuch der Optik (Verlag von S. Hirzel, Leibzig, 1906).

[76] Woollam, J. Ellipsometry, variable angle spectroscopic, in: J.G. Webster (Ed.). Wiley Encyclopedia of Electrical and Electronics Engineering, John Wiley and Sons, Inc., supplement 1 edn. (2000). P.111.

[77] https://www.thermoanalytics.com. Taitherm.

[78] Nyberg, S. \& Bohman, L. Assessing camouflage methods using textural features. Opt. Ing. 40, 1869-1876 (2001).

[79] Umov, N. Chromatische depolarisation durch lichtzerstreuung. Zeitschrift für Physik A Hadrons and Nuclei 6, 674-676 (1905).

[80] Ergin, T., Stenger, N., Brenner, P., Pendry, J. B. \& Wegener, M. Threedimensional invisibility cloak at optical wavelengths. Science 328, 337-339 (2010).

[81] Plamus, T. The Influence of Conductive Additives on the Mechanical Properties of Electronspun Mats, vol. Doctoral Thesis (Tallin University of Technology, 2018).

[82] Åkerlind, C., Fagerström, J., Hallberg, T. \& Kariis, H. Evaluation criteria for spectral design of camouflage. Proc.Spie 9653, 1-13 (2015).

[83] Björkert, S. \& Renhorn, I. Efficient polarimetric brdf transformations. Proc. SPIE 9820 (2016).

[84] Renhorn, I., Hallberg, T., Bergström, D. \& Boreman, G. Optics express 19 (2011).

[85] Renhorn, I., Hallberg, T. \& Boreman, G. Efficient polarimetric brdf model. Optics express 23, 31253-31273 (2015). 


\section{Papers}

The papers associated with this thesis have been removed for copyright reasons. For more details about these see:

http://urn.kb.se/resolve?urn=urn:nbn:se:liu:diva-169107 


\section{FACULTY OF SCIENCE AND ENGINEERING}

Linköping Studies in Science and Technology, Dissertation No. 2069, 2020

Department of Physics, Chemistry and Biology (IFM)

Linköping University

SE-581 83 Linköping, Sweden

www.liu.se

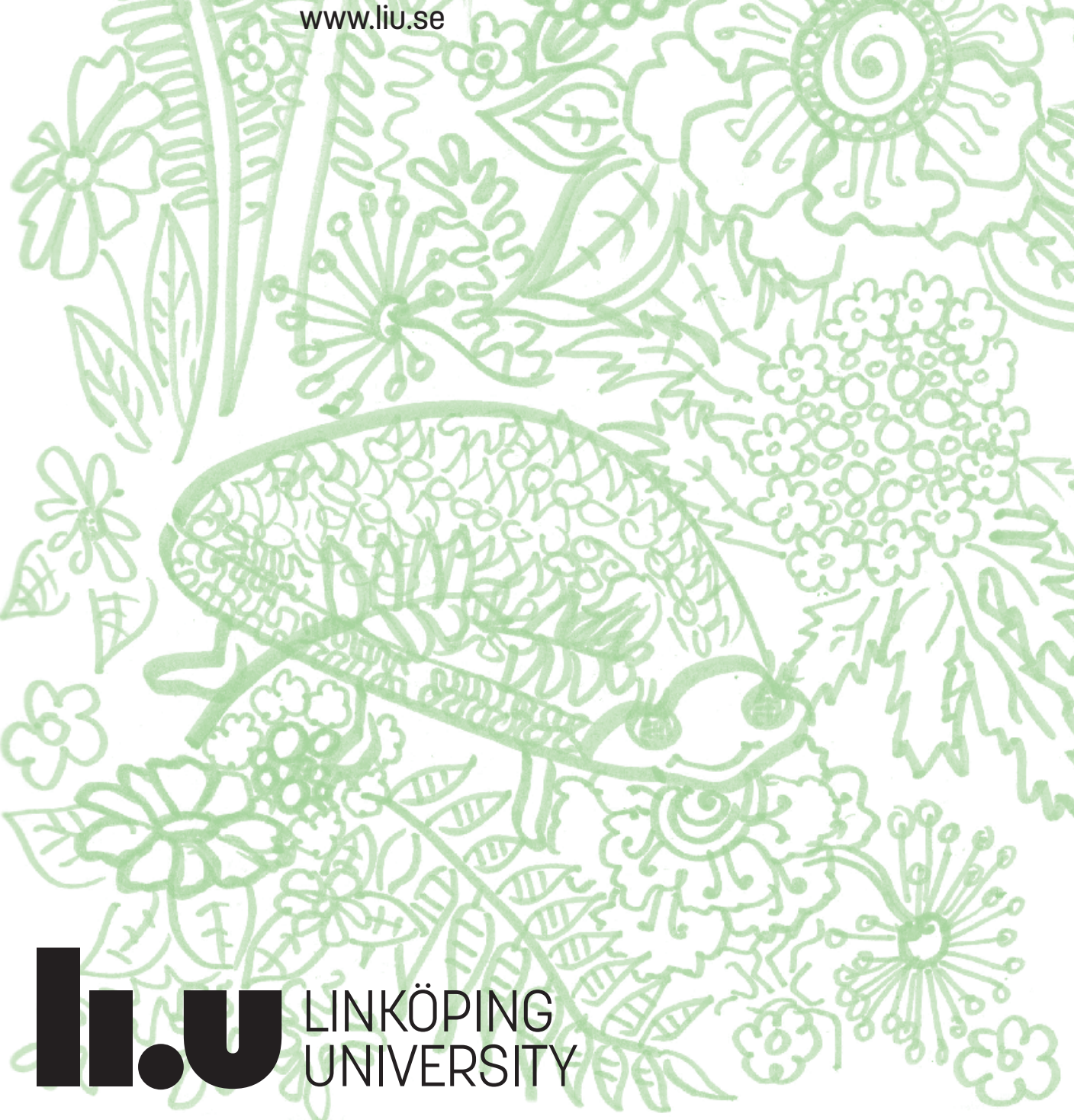

